\title{
DOPAMINE NEURON GLUTAMATE COTRANSMISSION: FREQUENCY-DEPENDENT MODULATION IN THE MESOVENTROMEDIAL PROJECTION
}

\author{
N. CHUHMA, ${ }^{*}$ W. Y. CHOI, S. MINGOTE AND \\ S. RAYPORT* \\ Department of Psychiatry, Columbia University; Department of Molec- \\ ular Therapeutics, New York State Psychiatric Institute, 1051 River- \\ side Drive, New York, NY 10032, USA
}

\begin{abstract}
Mesoventromedial dopamine neurons projecting from the medial ventral tegmental area to the ventromedial shell of the nucleus accumbens play a role in attributing incentive salience to environmental stimuli that predict important events, and appear to be particularly sensitive to the effects of psychostimulant drugs. Despite the observation that these dopamine neurons make up almost the entire complement of neurons in the projection, stimulating their cell bodies evokes a fast glutamatergic response in accumbens neurons. This is apparently due to dopamine neuron glutamate cotransmission, suggested by the extensive coexpression of vesicular glutamate transporter 2 (VGLUT2) in the neurons. To examine the interplay between the dopamine and glutamate signals, we used acute quasi-horizontal brain slices made from DAT-YFP mice in which the intact mesoventromedial projection can be visualized. Under current clamp, when dopamine neurons were stimulated repeatedly, dopamine neuron glutamate transmission showed dopamine-mediated facilitation, solely at higher, burst-firing frequencies. Facilitation was diminished under voltage clamp and flipped to inhibition by intracellular $\mathrm{Cs}^{+}$or GDP $\beta$ S, indicating that it was mediated postsynaptically. Postsynaptic facilitation was D1 mediated, required activation of NMDA receptors and closure of voltage gated $\mathrm{K}^{+}$-channels. When postsynaptic facilitation was blocked, D2-mediated presynaptic inhibition became apparent. These counterbalanced pre- and postsynaptic actions determine the frequency dependence of dopamine modulation; at lower firing frequencies dopamine modulation is not apparent, while at burst firing frequency postsynaptic facilitation dominates and dopamine becomes facilitatory. Dopamine neuron glutamate cotransmission may play an important role in encoding the incentive salience value of conditioned stimuli that activate goal-directed behaviors, and may be an important subtract for enduring drug-seeking behaviors. (๑) 2009 IBRO. Published by Elsevier Ltd. All rights reserved.
\end{abstract}

${ }^{*}$ Corresponding authors. Tel: +1-212-543-5641 (S. Rayport); +1-212543-6502 (N. Chuhma); fax: +1-212-504-3135.

E-mail addresses: sgr1@columbia.edu (S. Rayport); nc2027@columbia. edu (N. Chuhma).

Abbreviations: APV, D-(-)-2-amino-5-phosphonopentanoic acid; CNQX, 6-cyano-7-nitroquinoxaline-2,3-dione; CPP, conditioned place preference; CS, conditioned stimulus; CV, coefficient of variation; DA, dopamine; DAT, dopamine transporter; IPR, interpeduncular nucleus rostral subnucleus; ml, medial lemniscus; MSN, medium spiny neuron; MT, medial terminal nucleus of accessory optic tract; nAcc, nucleus accumbens; PBS, phosphate-buffered saline; ROI, region of interest; SN, substantia nigra; TH, tyrosine hydroxylase; VDNGR, VTA DA neuron glutamatergic response; VGLUT, vesicular glutamate transporter; VTA, ventral tegmental area; YFP, yellow-fluorescent protein.
Key words: mesolimbic projection, ventral tegmental area, addiction, schizophrenia, transgenic mice, VGLUT2.

Midbrain dopamine (DA) neurons in the ventral tegmental area (VTA) and substantial nigra (SN) project to the striatal complex in a topographic pattern; medial VTA DA neurons project ventromedially to the nucleus accumbens (nAcc) shell, while more lateral VTA and SN DA neurons project dorsolaterally to the nAcc core, striatum and prefrontal cortex (Haber et al., 2000; Ikemoto, 2007). The mesoventromedial projection, from the medial VTA to the medial shell of the nAcc plays a key role in mediating incentive salience to environmental stimuli predictive of behaviorally relevant events and appears to be especially sensitive to the effects of psychostimulant drugs (Everitt and Robbins, 2005; Ikemoto, 2007).

The greater sensitivity of the mesoventromedial DA neurons may arise from the increasingly recognized heterogeneity in midbrain DA neurons. There are broader differences between VTA and SN DA neurons and heterogeneity amonsgt VTA DA neurons (Korotkova et al., 2004; Liss and Roeper, 2007; Brischoux et al., 2009; Matsumoto and Hikosaka, 2009). The pattern of firing of VTA DA neurons differs from that of SN DA neurons (Wolfart et al., 2001; Liss and Roeper, 2007), as does the pattern of gene expression (Chung et al., 2005). Unlike SN DA neurons, VTA DA neurons do not show a clear electrophysiological signature (Margolis et al., 2006), arguing further for heterogeneity. VTA DA neurons can only be identified by electrophysiological criteria when their projection status is known (Lammel et al., 2008; Margolis et al., 2008). Heterogeneity is further accentuated by differences in modulatory afferent input (Cameron et al., 1997; Brischoux et al., 2009).

A further dimension in heterogeneity is in cotransmitter expression. There is evidence that VTA DA neurons use GABA (Olson and Nestler, 2007) as a cotransmitter, and in several DA neuron groups GABA cotransmission is extensive (Gall et al., 1987; Schimchowitsch et al., 1991; Maher and Westbrook, 2008). The more medial VTA DA neurons projecting to the ventromedial $\mathrm{nAcc}$ shell appear to be distinguished by glutamate cotransmission. Stimulation of the DA neurons in the medial VTA evokes fast excitatory responses in ventromedial nAcc neurons (Chuhma et al., 2004). Restricted retrograde tracer injections in the ventromedial $\mathrm{nAcc}$ shell reveal that $97 \%$ of retrogradely labeled neurons immunostain for the DA neuron marker tyrosine hydroxylase (TH) (Ikemoto, 2007), showing that

0306-4522/09 \$ - see front matter @ 2009 IBRO. Published by Elsevier Ltd. All rights reserved. doi:10.1016/j.neuroscience.2009.08.057 
the projection is almost exclusively made up of DA neurons, and arguing against the existence of a separate population of non-DAergic glutamatergic neurons.

A significant fraction of these medial VTA DA neurons coexpress vesicular glutamate transporter 2 (VGLUT2), both in their cell bodies and their synaptic varicosities in the nAcc (Kawano et al., 2006; Descarries et al., 2008), providing the anatomical basis for DA neuron glutamate cotransmission. VGLUT2 co-expression is seen in the majority of DA neurons in culture (Dal Bo et al., 2004); expression is developmentally regulated and decreases during postnatal development, so that in adulthood only about $\sim 20 \%$ of DA neurons appear to coexpress VGLUT2 (Descarries et al., 2008; Mendez et al., 2008). While these observations raise questions about the significance of cotransmission, the reported incidence may be an underestimate since detecting the immunoreactivity of VGLUTs in cell bodies can be challenging. The basis for DA neuron glutamate cotransmission was further questioned in a double in situ hybridization reporting practically no co-expression of VGLUT2 in VTA DA neurons (Yamaguchi et al., 2007). However, in situ hybridization may be still less sensitive than immunocytochemistry; moreover, this report did not include the medial VTA, where the highest incidence of VGLUT2 coexpression has been reported (Kawano et al., 2006).

The issue of synaptic heterogeneity further limits the interpretation of coexpression data obtained in DA neuron terminal fields. Immunohistochemical studies of DA neurons in culture (Sulzer et al., 1998; Joyce and Rayport, 2000) and in rat brain (Kawano et al., 2006) have shown that DA neurons have separate sets of dopaminergic and glutamatergic terminals. Glutamatergic terminals would not have been identified by costaining for $\mathrm{TH}$, or the alternate DA neuron marker vesicular monoamine transporter (VMAT2) so the morphological data supporting DA neuron glutamate cotransmission in target areas (Kawano et al., 2006; Descarries et al., 2008) likely also underestimate the incidence of cotransmission.

In this report, we focused on cotransmission in the mesoventromedial DA neuron projection. We show first by careful double immunostaining that significant numbers of the DA neurons giving rise to the projection are immunoreactive for VGLUT2, both in juvenile and adult mice. Thus, with stimulation in the medial VTA and recording in the ventromedial nAcc shell, we can be confident that evoked glutamatergic responses are due to DA neuron glutamate cotransmission. Glutamate receptor antagonists block the fast synaptic actions of ventromedial DA neuron completely, consistent with the now generally accepted view that DA neuron actions in target areas are modulatory. Indeed, we find that DA exerts its actions via modulation of the glutamatergic response. Analysis of the DA modulation reveals counterbalanced pre and postsynaptic effects, so that at slower firing frequencies DA exerts no net effect, while at burst firing frequencies DA facilitates the glutamatergic cotransmission.

\section{EXPERIMENTAL PROCEDURES}

\section{DAT-YFP mice}

Animal procedures followed the guidelines of the National Institutes of Health Guide for the Care and Use of Laboratory Animals, and were approved by the Institutional Animal Care and Use Committees of Columbia University and the New York State Psychiatric Institute. A total of 143 mice were used for the physiological studies. Mice were genotyped by PCR analysis of genomic DNA from tail samples (see Chuhma et al., 2004, for primer sequences). Electrophysiological studies were conducted in brain slices made from DAT-YFP mice with fluorescent DA neurons, maintained on a mixed 129Sv/C57BL6J background. Wild-type littermates or mice of similar background were used for immnocytochemical studies. DAT-YFP mice were generated by breeding $\mathrm{DAT}^{\mathrm{cre} /+}$ mice expressing cre from the dopamine transporter (DAT) locus (Zhuang et al., 2005) with ROSA26 floxSTOP-YFP reporter mice (Srinivas et al., 2001). DAT ${ }^{\text {cre/+ }}$ males were crossed with hetero or homozygous ROSA26 floxSTOP-YFP females; data from pups born to heterozygous or homozygous dams were pooled, as there were no maternal genotype effects seen in the synaptic responses. For some experiments involving current injection into medium spiny neurons (MSNs), where DA neuron visualization was not required, we used $\mathrm{DAT}^{\mathrm{cre} /+}$ mice; again, since there was no difference in the results obtained between the single and double mutants, data were pooled.

\section{Immunocytochemistry}

Wild-type mice at either 3.5 week (juvenile) or 6 week (adult) were anesthetized with nembutal $(100 \mathrm{mg} / \mathrm{kg})$ and rapidly perfused intracardially with chilled phosphate-buffered saline (PBS, in $\mathrm{mM}$ : $136.9 \mathrm{NaCl}, 2.7 \mathrm{KCl}, 1.5 \mathrm{KH}_{2} \mathrm{PO}_{4}, 8.1 \mathrm{Na}_{2} \mathrm{HPO}_{4}$ ) containing $0.01 \% \mathrm{v} / \mathrm{v}$ of a mixture of ketamine $(70 \mathrm{mg} / \mathrm{ml})$ and xylazine $(60$ $\mathrm{mg} / \mathrm{ml}$ ), followed by perfusion with the same solution containing $4 \%$ paraformaldehyde. The combined use of ice cold perfusate (Geddes et al., 1999) and inclusion of anesthetic in the perfusate and fixation solutions (Sulzer et al., 1998) dramatically reduces excitotoxicity by limiting glutamate release, presumably improving immunocytochemical visualization of synaptic vesicle-related antigens such as VGLUT2. Brains were removed and postfixed overnight at $4{ }^{\circ} \mathrm{C}$ in the $4 \%$ paraformaldehyde in PBS, cryoprotected in a graded series of sucrose solutions $(10,20$, then $30 \%)$, and $50 \mu \mathrm{m}$ coronal or horizontal frozen sections cut (Leica Cryostat). Free-floating sections were washed in PBS, aldehydes quenched with glycine $(100 \mathrm{mM})$, and non-specific binding blocked with $10 \%$ normal donkey serum (Chemicon/Millipore, Temecula, CA, USA) and $0.1 \%$ Triton X-100 for $1 \mathrm{~h}$. Sections were incubated with primary antiserum against $\mathrm{TH}$ (rabbit polyclonal, 1:2000; Chemicon/Millipore AB152) and VGLUT2 (mouse monoclonal, 1:250, Chemicon/Millipore MAB5504) in PBS containing $0.05 \%$ Triton $\mathrm{X}-100$ and $2 \%$ normal donkey serum, on a shaker at $4{ }^{\circ} \mathrm{C}$ for $24 \mathrm{~h}$. The specificity of the primary antiserum against VGLUT2 has been previously validated by Western blotting (Kashani et al., 2007), and by comparison with other commercially available antisera (Hrabovszky et al., 2006; Wassle et al., 2006; Kashani et al., 2007). Sections were washed and incubated with species-absorbed secondary antibodies conjugated with Fluorescein (1:200, Chemicon/Millipore, AP 182F) for TH or CY3 (1:200, Chemicon/Millipore, AP192C) for VGLUT2, mounted in Prolong Gold aqueous medium (Invitrogen), cover slipped and stored at $4{ }^{\circ} \mathrm{C}$ till imaging was done.

\section{Confocal image acquisition and analysis}

Images were acquired using a LSM 510 confocal laser-scanning microscope (Zeiss) equipped with a $488 / 543 \mathrm{~nm}$ primary beam splitter, using a $488 \mathrm{~nm}$ argon laser for fluorescein (500-550 nm band-pass) and a $543 \mathrm{~nm}$ helium-neon laser for CY3 (560 nm 
long-pass). Images were taken with either $10 \times(0.5 \mathrm{NA})$ or $63 \times$ oil (1.25 NA) objectives with a pinhole size between 119 and $123 \mu \mathrm{m}$ (set to maximum 1 Airy unit for each channel and matched for equivalently thick optical slices) and $1 \times$ optical zoom setting, with Z-stepping at $<0.7 \mu \mathrm{m}$. For each region of interest, stacks of $\sim 10$ confocal sections were acquired; minimally, five sections were acquired. To minimize or rule out bleed-through between the two channels, confocal image stacks were acquired sequentially for the two color channels. To rule out bleed-through further, additional images were acquired with less optimized filter sets with slightly higher (e.g. $585 \mathrm{~nm}$ long-pass for CY3 signal) or lower spectral ranges to establish that the images in the two color channels did not change qualitatively; while the resulting images were dimmer (with the less optimized filters), the lack of any qualitative change in the images and colocalization counts argue further against bleed-through. Confocal stacks were linearly adjusted for levels, contrast and brightness using ImageJ (WS Rasband, National Institutes of Health, Bethesda, MD, USA; http:// rsb.info.nih.gov/ij/, 1997-2008). Illustrations were prepared from series of confocal planes or by z-projecting stacks using maximum pixel intensities. The z-projected images were downsized to byte format for preparation of plates in Illustrator (Adobe).

Cells were counted in confocal stacks using ImageJ. The extent of colocalization was based on strict scoring of cell immunoreactivity. For this, each cell was observed in all available confocal z-sections and scored as immuno-positive only when the cytoplasmic and proximal dendritic signal were clearly distinguishable from the surrounding neuropil, based on both morphology and fluorescence intensity, and the immuonegative nucleus was evident in at least two adjacent $z$-sections. Conservative guidelines were followed so as to count cells as immuno-positive only when these criteria were met reliably. Following this counting protocol, a second observer (blind to the first observer's results) verified the results. A total of 556 cells were counted in sections from five mice.

\section{Brain slice electrophysiology}

$\mathrm{DAT}^{\text {cre/+ }}$ or DAT-YFP mice (P20-P60) were anesthetized with ketamine $(100 \mathrm{mg} / \mathrm{kg}) / x y l a z i n e(15 \mathrm{mg} / \mathrm{kg})$, i.p. After confirmation of full anesthesia by the lack of a response to paw pressure, mice were decapitated. Brains were removed in ice cold high-glucose artificial cerebrospinal fluid (aCSF) saturated with carbogen (95\% $\mathrm{O}_{2} ; 5 \% \mathrm{CO}_{2}$ ). The composition of the high-glucose aCSF was, in mM: $75 \mathrm{NaCl}, 2.5 \mathrm{KCl}, 26 \mathrm{NaHCO}_{3}, 1.25 \mathrm{NaH}_{2} \mathrm{PO}_{4}, 0.7 \mathrm{CaCl}_{2}, 2$ $\mathrm{MgCl}_{2}$ and 100 glucose, adjusted to $\mathrm{pH}$ 7.4. The entire brain was placed ventral surface up, positioned with the base of the brain oriented in the horizontal plane. Successive thin slices were cut with a vibrating blade microtome (model NVSLM1 Vibroslice, World Precision Instruments, Sarasota, FL, USA or a model VT1200S, Leica) till the near rostral extent of the cerebral peduncles and the olfactory bulbs were reached. Then a $500 \mu \mathrm{m}$ thick slice encompassing the entire mesoaccumbens projection was cut. When cut correctly, the rostral branches of the anterior commissure were seen in the remaining chunk of uncut brain. In this slice preparation, a small population of coplanar mesoaccumbens axons are preserved (Chuhma et al., 2004). The parameters for preparing the slice are quite stringent; if the angle or level at which the slice is cut is just slightly off, fluorescent DA neuron axons cannot be traced from the VTA to the nAcc, and neither DA release nor an excitatory response can be recorded in the nAcc. The single mesoaccumbens slice obtained from each animal was cut along the midline so that two experiments could be conducted per animal. Slices were preincubated in high-glucose aCSF saturated with carbogen for $1 \mathrm{~h}$ at room temperature prior to experiments. Slices were then transferred to the recording chamber (submerged, $500 \mu \mathrm{l}$ volume) on the stage of a BX61W fluorescence microscope (Olympus), positioned dorsal surface up, and visualized with a $60 \times$ water-immersion objective.
Evoked synaptic responses were recorded in whole cell clamp mode from MSNs in the nAcc. Recordings were made in the ventromedial nAcc shell. MSNs were visualized using enhanced visible light differential interference contrast (DIC) optics with a CCD camera (model OLY-150; Olympus), and identified by their characteristic size and deep resting membrane potential (greater than $-70 \mathrm{mV}$, Jiang and North, 1991). Recording patch pipettes were fabricated from standard wall borosilicate glass capillary with filament (World Precision Instruments). Pipette resistance was 6-8 $\mathrm{M} \Omega$ for most recordings, but 3-5 $\mathrm{M} \Omega$ for GDP $\beta$ S recording. Composition of standard pipette solution was (in $\mathrm{mM}$ ): $140 \mathrm{~K}^{+}$gluconate, 10 HEPES, $0.1 \mathrm{CaCl}_{2}$, $2 \mathrm{MgCl}_{2}$, 1 EGTA, 2 ATP- $\mathrm{Na}_{2}$ and 0.1 GTP-Na $a_{2}, \mathrm{pH}$ 7.3. To block unclamped and antidromic $\mathrm{Na}^{+}$currents, $5 \mathrm{mM}$ Lidocaine $\mathrm{N}$-ethyl bromide (QX-314, Sigma Aldrich, St. Louis, MO, USA) was added to the pipette solution. Membrane potentials were corrected off-line for the liquid junction potential $(\sim 15 \mathrm{mV})$. For $\mathrm{Cs}^{+}$-based pipette solution, $\mathrm{K}^{+}$-gluconate in the standard pipette solution was replaced with $\mathrm{Cs}^{+}$-gluconate. For GDP $\beta$ S experiment, GTP- $\mathrm{Na}_{2}$ in the standard pipette solution was replaced with 1-2 mM GDP $\beta$ S tri-lithium salt (Sigma-Aldrich). The recording chamber was continuously perfused $(1 \mathrm{ml} /$ min) with standard aCSF (in mM): $125 \mathrm{NaCl}, 2.5 \mathrm{KCl}, 25 \mathrm{NaHCO}_{3}$, $1.25 \mathrm{NaH}_{2} \mathrm{PO}_{4}, 2 \mathrm{CaCl}_{2}, 1 \mathrm{MgCl}_{2}$ and 25 glucose, $\mathrm{pH} 7.4$, saturated with carbogen, to which was added the selective $\mathrm{GABA}_{\mathrm{A}}$ antagonist SR95531 (Gabazine, $10 \mu \mathrm{M}$; Tocris Bioscience, Ellisville, MO, USA).

Current clamp recordings were mainly performed with an Axoclamp 2A (Molecular Devices, Union City, CA, USA). Voltage clamp recordings were performed with an Axopatch 200B (Molecular Devices). Holding potential was $-85 \mathrm{mV}$, unless otherwise stated. In experiments comparing current and voltage clamp recordings, current clamp recordings were done using the fast current clamp mode of the Axopatch 200B. There was no appreciable difference in the current clamp recordings obtained with the Axoclamp $2 \mathrm{~A}$ and the fast current clamp mode of the Axopatch 200B, so the data were pooled. No series resistance $(20-45 \mathrm{M} \Omega$ ) compensation was done in synaptic recordings to minimize baseline noise. The size and time course of the synaptic response, which was small $(\sim 30 \mathrm{pA})$, did not change with series resistance compensation (both on-line and off-line compensation). For current injection experiments, the injected current (simulated glutamate synaptic current) was generated from a 30-trace average of the synaptic current evoked by $20 \mathrm{~Hz}$ stimulation gathered from three cells. For voltage clamp recording of whole cell $\mathrm{K}^{+}$currents, $1 \mu \mathrm{M}$ tetrodotoxin and $100 \mu \mathrm{M} \mathrm{CdCl}_{2}$ were added to the standard aCSF to block $\mathrm{Na}^{+}$-channels and $\mathrm{Ca}^{2+}$ channels, respectively; the concentration of $\mathrm{CaCl}_{2}$ was reduced to $0.5 \mathrm{mM}$ and that of $\mathrm{MgCl}_{2}$ increased to $2 \mathrm{mM}$. Series resistance was compensated online by $75 \%-80 \%$, and $10 \mathrm{mV}$ voltage steps ( $300 \mathrm{~ms}$ duration, from $-140 \mathrm{mV}$ to $+40 \mathrm{mV}$ ) were applied from $-80 \mathrm{mV}$.

Amphotericin B perforated patch recording was done to obviate washout issues. Recording pipettes (2-4 $M \Omega$ ) were tip filled with Amphotericin-free $\mathrm{K}^{+}$-gluconate solution and back filled with Amphotericin $\mathrm{K}^{+}$-gluconate solution, containing $240 \mu \mathrm{g} / \mathrm{ml} \mathrm{Am-}$ photericin $\mathrm{B}$ (Sigma-Aldrich) in $\mathrm{K}^{+}$-gluconate internal solution without QX314.

\section{Stimulation}

DA neurons in the VTA were identified by yellow-fluorescent protein (YFP) fluorescence (EYFP filter, Omega Optical, Brattleboro, VT, USA). A focal bipolar tungsten stimulus electrode (tip diameter $15 \mu \mathrm{m}$, tip separation $400 \mu \mathrm{m}$, World Precision Instruments) was placed on the medial rostral edge of the VTA, at the exit of the median forebrain bundle, close to the midline, to avoid activation of cortical efferent fibers in the internal capsule. Quasi-single pulse stimulation was delivered in a high-frequency train of three $1 \mathrm{kHz}$ pulses (1-2 $\mathrm{mA}$ ) by a SD9 stimulator (AstroMed/Grass 
Technologies, West Warwick, RI, USA) via a BSI-950 stimulus isolation unit (Dagan, Minneapolis, MN, USA). Slow stimulation at $0.2 \mathrm{~Hz}$ (of quasi-single pulses) was delivered continuously. For higher frequency stimulation $(1,4,10$ and $20 \mathrm{~Hz}$ ), trains of five pulses were delivered under computer control with a 1 min intertrain interval, to avoid effects of the residual DA released by the preceding train. For local stimulation of the mesoaccumbens fibers, focal stimulation (also quasi-single pulses) was delivered $\sim 300 \mu \mathrm{m}$ caudal to the recorded cell, at the point where the fibers enter the nAcc. Stimulus intensities were kept below $200 \mu \mathrm{A}$ to limit current spread. Most experiments were done at room temperature $\left(22-24^{\circ} \mathrm{C}\right)$. For experiments addressing whether a direct DA signal might be revealed at physiological temperatures, the recording chamber solution was warmed to $32-34{ }^{\circ} \mathrm{C}$ (TC 344B, Warner Instruments).

\section{Drugs}

SR95531 (Gabazine), (-)-quinpirole, sulpiride, SCH23390, D-(-)-2amino-5-phosphonopentanoic acid (APV), 6-cyano-7-nitroquinoxaline-2,3-dione (CNQX), (+)-MK-801 (dizocilpine) and scopolamine were obtained from Tocris Bioscience. Nomifensine, DA; SKF81950, QX-314 and GDP $\beta$ S were obtained from Sigma-Aldrich. GDP $\beta$ S internal solution was prepared freshly from powder just before recording. Stock solutions $(500-1000 x)$ were stored at $-20{ }^{\circ} \mathrm{C}$ prior to use and discarded at the end of the day. Ascorbic acid $(10 \mu \mathrm{M})$ was included in DA solutions to retard oxidization. Drug concentrations used were the minimum necessary to obtain full action within $10 \mathrm{~min}$, given the diffusion times in thick slices $(500 \mu \mathrm{m})$.

\section{Dataset}

A total of $140 \mathrm{MSNs}$ with intact connections were recorded in our studies of mesoaccumbens synaptic connections. To find connections, the stimulus electrode was placed as described above, and not moved; successive recordings were obtained from MSNs until a connection was found. Slices were discarded if no connection was found after recording from $12 \mathrm{MSNs}$. If recordings were unstable or connections were weak (less than $10 \mathrm{pA}$ ) or unreliable, the data were also discarded. On average, we recorded from nine MSNs until a usable connection was found. A total of 36 cells were used in the postsynaptic current injection studies. To address whether the glutamate cotransmission persists in adulthood, we recorded separately from a juvenile group (P20-P34) and a mature group (P42-P60) of mice. The age range for the mature group was based on observations that most of the transition from immature behavior pattern to the mature one happens around P42 (Spear, 2000). Since there was no apparent developmental difference in the DA modulation of the synaptic responses between the juvenile and mature groups, the data were pooled.

\section{Data analysis}

Electrophysiological recordings were filtered at $5 \mathrm{kHz}$ using a 4-pole Bessel filter, and digitized (ITC-16 Interface, Instrutech, Port Washington, NY, USA) at $100 \mu$ s intervals for $0.2 \mathrm{~Hz}$ stimulation and at $200 \mu \mathrm{s}$ intervals for the other stimulus protocols, using Pulse Control 4.7 (Richard J. Bookman, University of Miami, Miami, FL, USA; HEKA/InstruTech, Baltimore, NY, USA) running under Igor Pro 4.04 (WaveMetrics, Lake Oswego, OR, USA) on a Power Macintosh (Apple, Cupertino, CA, USA). Further analysis was done using Igor Pro and Axograph 3.6 (Molecular Devices). To improve the presentation of synaptic responses in the figures, stimulus artifacts were truncated. For responses to train stimulation, the average amplitude of the response to the second to fifth pulses was measured from the pre-stimulus baseline; we made the assumption that the response to the first pulse was not subject to the effects of coreleased DA. For postsynaptic current injection experiments, the average amplitude of the response to all five stimuli was measured (since there was no DA corelease). Drug effects were expressed as the percent of the preceding control response (\% control).

To confirm presynaptic DA effects, we performed a fluctuation analysis of EPSC amplitude (Clements and Silver, 2000), measuring the coefficient of variation (CV). With a simple binomial model of synaptic vesicle release, CV of EPSC amplitude is calculated as:

$$
C V=\frac{\sigma}{\mu}=\sqrt{\frac{1}{n}\left(\frac{1}{p}-1\right)}
$$

where $\mu$ is the mean and $\sigma$ the standard deviation of EPSC amplitude, $\mathrm{n}$ is the number of presynaptic release sites, and $\mathrm{p}$ is the release probability for a single vesicle. This CV method allows for discrimination of pre- or postsynaptic modulation, at relatively low release probability synapses; the method cannot, however, detect whether the presynaptic change is due to a change in release probability or in the number of release sites. The glutamatergic responses we studied were small in amplitude, with a relatively large fluctuation and a high failure rate $(\sim 5 \%)$, even including cells with low failure rates, making them amenable to $\mathrm{CV}$ analysis. In cells with stable responses and lower failure rates, we collected 50 consecutive traces before and after drug application.

Statistical analyses were done in Statview 5.01 (SAS Institute, S.Cary, NC, USA). Data are reported as mean \pm SEM, unless otherwise stated.

\section{RESULTS}

\section{TH and VGLUT2 colocalization in the VTA DA neurons}

To evaluate the cellular basis for DA neuron glutamate cotransmission, we first immunostained medial ventral midbrain sections for the DA neuron marker $\mathrm{TH}$ and for VGLUT2 (Fig. 1). It is well known that induction of VGLUT expression is sufficient to confer a glutamatergic phenotype (Takamori et al., 2000). Previous work (Kawano et al., 2006; Mendez et al., 2008) has shown that DA neurons express VGLUT2, but not VGLUT1 or VGLUT3 (Mendez et al., 2008). We validated the VGLUT2 antiserum used based on subcellular and regional staining patterns (see Fig. S1, S2 in the Supplemental Information). In juvenile mouse (3.5 week old), low magnification views (Fig. 1A) revealed extensive overlap in cellular staining for $\mathrm{TH}$ and VGLUT2. At higher magnification (Fig. 1 $\mathrm{B}_{1}$ ), most cells were immunoreactive for both TH and VGLUT2. Further enlargement of a region of interest in a confocal z-series (Fig. $1 \mathrm{~B}_{2}$ ) showed that the subcellular distribution of $\mathrm{TH}$ and VGLUT2 immunoreactivity was cytoplasmic; in addition, punctate VGLUT2 immunoreactivity was seen in the neuropil, presumably in afferent synaptic terminals. Some neuronal cell bodies were decorated with clearly distinguishable puncta of VGLUT2 staining (Fig. S1). Occasional TH-/VGLUT2+ cells were evident (arrows, Fig. $1 \mathrm{~B}_{2}$ ). In juvenile mice ( $n=2$ mice), $79 \%$ of all immunopositive cells in the medial VTA ( $n=208$ cells counted) were $\mathrm{TH}+/$ VGLUT2,$+ 6 \%$ were TH+/VGLUT2- and $15 \%$ were TH-/VGLUT2+. In adult mice ( $n=3$ mice), $48 \%$ of immunoreactive cells ( $n=348$ cells) were TH+/VGLUT2+, $40 \%$ were $\mathrm{TH}+$ /VGLUT2- and $12 \%$ were TH-/VGLUT2+. 

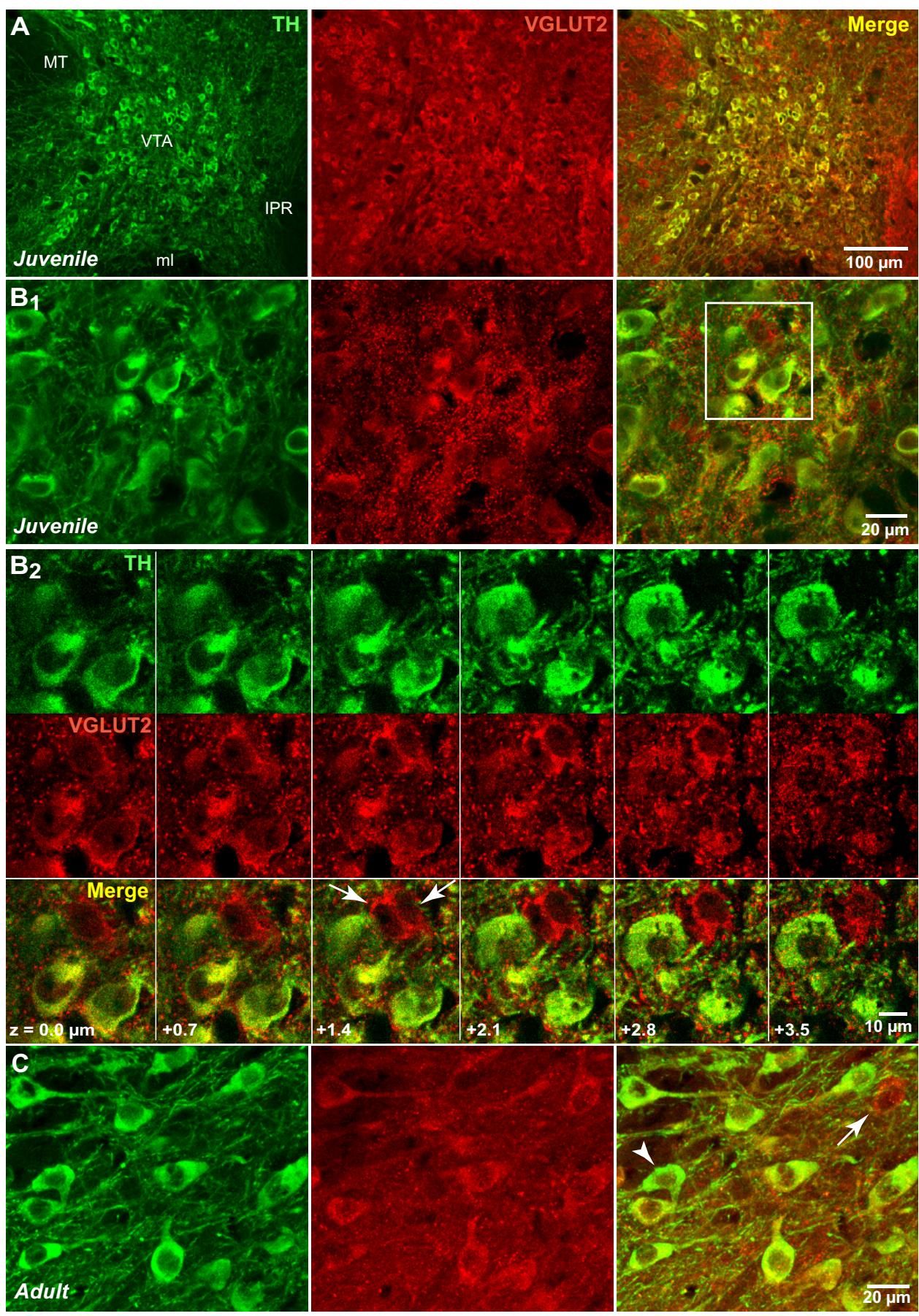

Fig. 1. VGLUT2 immunoreactivity in VTA DA neurons. To assess the transmitter status of VTA DA neurons, VTA sections were double immunostained for the DA neuron marker TH (green) and for VGLUT2 (red). Confocal z-series of 5-10 sections were acquired; z-projections are shown, except for the confocal z-series in $B_{2}$. (A) In a low magnification (10x) view from a horizontal section (rostral is towards the top and the midline to the right) from a juvenile mouse, many DA neurons are visualized by TH immunoreactivity (left panel). Most also immunostain for VGLUT2 (middle panel), as is evident in the merged image (right panel; colocalization appears yellow). ( $\left.B_{1}\right)$ At higher magnification (63x, same section), most TH immunoreactive neurons are also immunopositive for VGLUT2. $\left(B_{2}\right)$ Expanding the region of interest (ROI) outlined in $\left(B_{1}\right)$, and showing the individual confocal sections (as used for cell counts) reveals two patterns of VGLUT2 immunoreactivity, cytoplasmic and punctate; punctate immunoreactivity is most likely in afferent terminals. In this ROI, there were five neurons, three TH+/VGLUT2+ and two TH-/ VGLUT2+ (arrows). (C) In a higher power (63x) coronal VTA section from an adult mouse, most neurons are TH+/VGLUT2+; the arrowhead denotes a TH+/VGLUT2-neuron, and the arrow denotes a TH-NGLUT2+neuron. MT, medial terminal nucleus of accessory optic tract; IPR, interpeduncular nucleus rostral subnucleus; ml, medial lemniscus.

Thus in both juvenile and adult mice, the majority of DA neurons were VGLUT2 immunoreactive, and only a minor- ity of immunoreactive neurons were solely VGLUT2 immunoreactive. 
DA release in the medial shell of the nAcc had no fast synaptic actions

To study DA neuron synaptic actions, we made thick, appropriately canted horizontal slices from DAT-YFP mice with fluorescent DA neurons (Zhuang et al., 2005) encompassing the mesoventromedial projection. The $\mathrm{GABA}_{\mathrm{A}}$ selective antagonist SR95531 (10 $\mu \mathrm{M})$ was continuously applied in all experiments to eliminate GABAergic signals. Under these conditions (as we observed previously, Chuhma et al., 2004), stimulating a small number of DA neurons in the medial VTA evoked a fast excitatory response in MSNs in the ventromedial nAcc shell. This excitatory response was glutamatergic, as it was completely blocked by the AMPA/kainite antagonist CNQX (Fig. 2A). To look more carefully for direct postsynaptic actions of released DA, we enhanced DA effects with the DA uptake blocker nomifensine (10 $\mu \mathrm{M}$; Fig. 2A), and stimulated DA neurons at $20 \mathrm{~Hz}$ to mimic burst firing and maximize DA output (viz. Suaud-Chagny et al., 1992). Under both current clamp (Fig. 2A1) and voltage clamp (Fig. 2A2), the excitatory response was blocked completely by CNQX ( $n=8$ cells). DA neurons thus do not appear to elicit subsecond IPSCs in the nAcc, as they do in the VTA (Beckstead et al., 2004; Vandecasteele et al., 2008). However, it was possible that we missed a direct DA action as a consequence of having cut the axons of many DA neurons while making the mesoaccumbens slice (we have estimated that $\sim 5 \%$ of DA neuron axons remain intact based on the magnitude of voltammetrically-detectable DA release with VTA stimulation, Chuhma et al., 2004).

To activate more DA neuron inputs, we stimulated DA neuron axons where they enter the nAcc (Fig. 2B). This generated fast excitatory synaptic responses with a time course very similar to the responses evoked by the medial VTA stimulation, but larger in amplitude $(6.3 \pm 2.0 \mathrm{mV}$, $26.1 \pm 6.0 \mathrm{pA}, n=8$ cells for VTA stimulation, $20.6 \pm 3.9 \mathrm{mV}$, $129.0 \pm 31.1 \mathrm{pA}, n=10$ for local stimulation). This stimulation also generated DA release, confirmed by enhancement of the excitatory responses by nomifensine. Since the local stimulation activated multiple inputs, we used a cocktail of CNQX, MK-801 (NMDA antagonist, $10 \mu \mathrm{M}$ ), CGP55845 (GABA ${ }_{\mathrm{B}}$ antagonist, $3 \mu \mathrm{M}$ ), scopolamine (muscarinic antagonist, $1 \mu \mathrm{M}$ ), and SR95531 to isolate the direct postsynaptic actions of DA. As with VTA stimulation, the DA response sparing antagonist cocktail blocked the excitatory response with local stimulation, under both current (Fig. 2B1) and voltage clamp (Fig. 2B2; $n=10$ cells). Thus, the lack of a postsynaptic DA-mediated subsecond response was not an artifact of having severed many DA neuron axons during sectioning, but was due rather to the fact that in the nAcc synaptically-released DA has no direct, fast effect on postsynaptic ion channels.

The fast synaptic response was completely blocked by CNQX in juvenile (P20-P34) and mature (P42-P60) slices, both at room temperature and at near physiological temperature $\left(32-33{ }^{\circ} \mathrm{C}\right.$, see Supplementary Information Fig. S3), showing further that the lack of a subsecond DA action in the nAcc was not due to immaturity of DA neuron synapses or to
A1 VTA stimulation

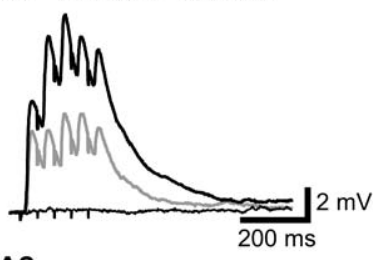

B1 Local stimulation

A2

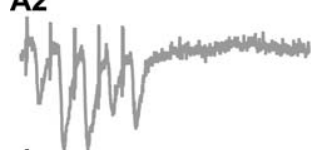

B2
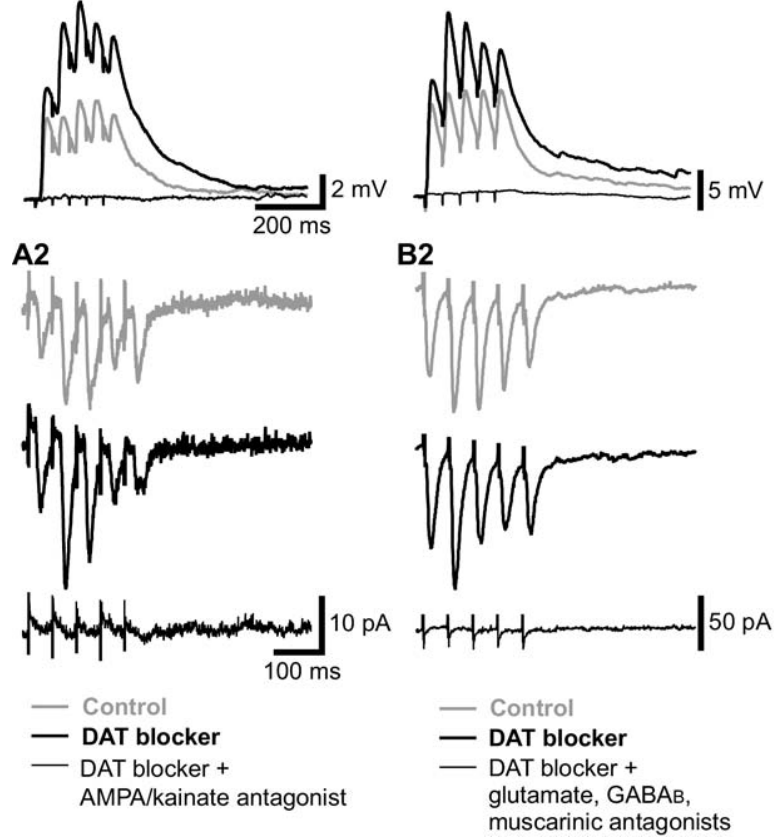

Fig. 2. Fast DA neuron actions in the nAcc are glutamatergic. (A) VTA stimulation. Activating a small number of DA neurons with focal stimulation in the VTA produced a fast excitatory response in the recorded MSN (grey traces), recorded either under current (A1) or voltage clamp (A2). To increase sensitivity for the detection of small DA neuron-evoked responses, DA effects were enhanced with the reuptake inhibitor nomifensine (10 $\mu \mathrm{M}$; thick black traces). Despite the enhanced DA effect, the AMPA antagonist CNQX (40 $\mu \mathrm{M}$; thin black traces) completely blocked the fast synaptic response, revealing no subsecond DA actions. All control records, in this and subsequent figures were obtained under continuous $\mathrm{GABA}_{\mathrm{A}}$ receptor blockade (SR95531, $10 \mu \mathrm{M}$ ); records shown are the averages of five traces. (B) Local stimulation in the $\mathrm{nAcc}$, recorded from a different neuron. DA neuron axons were activated by focal stimulation, delivered about 300 $\mu \mathrm{m}$ caudal to the recorded MSN at the border of the nAcc. Stimulus intensity was minimized to avoid direct activation of postsynaptic ion channels by current spread. Stimulus intensity for local stimulation ranged from $0.1-0.2 \mathrm{~mA}$ (more intense stimulation produced an artifact that distorted the evoked response); VTA stimulation ranged from 1-2 $\mathrm{mA}$ (which evoked a maximal response). Application of nomifensine $(10 \mu \mathrm{M}$, black traces) again produced an enhancement of the response, confirming that the stimulation activated DA neuron axons. Then DAergic actions were isolated by blocking all other likely neurotransmitter actions with a cocktail (thin black traces) of: CNQX (40 $\mu \mathrm{M}), \mathrm{MK}-801$ (NMDA antagonist, $10 \mu \mathrm{M})$, CGP55845 (GABA ${ }_{\mathrm{B}}$ antagonist, $3 \mu \mathrm{M}$ ), and scopolamine (muscarinic antagonist, $1 \mu \mathrm{M}$ ). Under either current (B1) or voltage clamp (B2), the response to the local stimulation was completely blocked, revealing no subsecond DAergic action.

sub-physiological recording temperature. Thus, the fast synaptic actions of mesoventromedial DA neurons evoked by VTA stimulation appear to be glutamatergic. Henceforth, we refer to this excitatory synaptic signal as the VTA DA neuron glutamatergic response (VDNGR).

\section{Frequency-dependence of DA modulation of the VDNGR}

Presumably then, the actions of DA in the mesoventromedial projection are modulatory. To explore DA modulation 

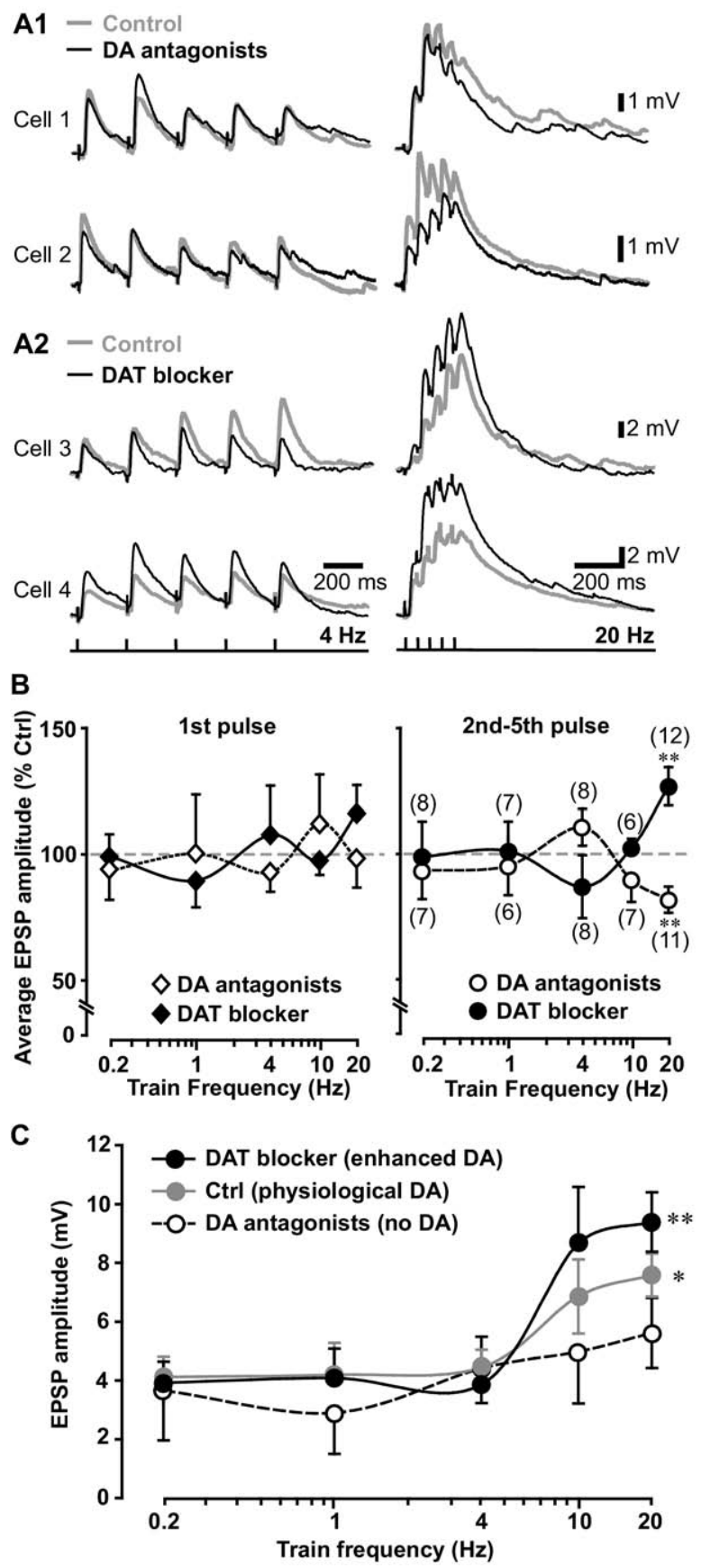

Fig. 3. Frequency dependence of DA modulation of the VDNGR. (A) The VDNGR was evoked at 0.2, 1, 4, 10 and $20 \mathrm{~Hz}$ in MSNs by VTA stimulation, under current clamp. Traces for $4 \mathrm{~Hz}$ (left) and $20 \mathrm{~Hz}$ (right) stimulation are shown (stimulus timing is indicated beneath the traces); control traces (gabazine only) are shown in grey. (A1) Blocking DA action with $\mathrm{SCH} 23390$ (D1 antagonist, $10 \mu \mathrm{M})$ and sulpiride (D2 antagonist, $10 \mu \mathrm{M}$, black traces) inhibited the VDNGR at $20 \mathrm{~Hz}$ selectively. Sample traces recorded from two different cells in different slices are shown. (A2) Inhibition of DA reuptake with nomifensine (10 $\mu \mathrm{M}$, black traces) had variable effects at $4 \mathrm{~Hz}$ and enhanced the glutamatergic response at $20 \mathrm{~Hz}$. (B) Summary of frequency dependence of DA modulation of the VDNGR. We compared the response to the first stimulation pulse (left), and the average response to the second to fifth stimulation pulses (right). Since the protocol for $0.2 \mathrm{~Hz}$ stimulation (10 consecutive stimulation at $0.2 \mathrm{~Hz}$ ) was different, the of the VDNGR, we stimulated medial VTA DA neurons at five frequencies: 0.2, 1, 4, 10 and $20 \mathrm{~Hz}$ (Fig. 3), corresponding to the range of firing frequencies of DA neurons recognized in vivo, namely, $0.2 \mathrm{~Hz}$ relatively quiescent, 4 $\mathrm{Hz}$ tonic firing, $20 \mathrm{~Hz}$ burst firing, with intermediate frequencies, $1 \mathrm{H}$ and $10 \mathrm{~Hz}$. We expected to see evidence of frequency-dependent DA release, as slices from the nAcc shell (in contrast to those from the dorsal striatum) show increased DA tone with $4 \mathrm{~Hz}$ stimulation and a surge in DA release with $20 \mathrm{~Hz}$ burst frequency stimulation (Zhang et al., 2009b). Stimulation was applied as a five-pulse train, except for $0.2 \mathrm{~Hz}$ stimulation where 10 pulses were collected. Train stimulation was delivered at $1 \mathrm{~min}$ intervals to allow the residual effects of the DA released by the preceding train to dissipate (viz. Schmitz et al., 2003). Given that the onset of DA action is typically in the range of $\sim 20 \mathrm{~ms}$ (Schmitz et al., 2003; Vandecasteele et al., 2008), the first pulse in the train should not be subject to modulation by simultaneously released DA. Therefore, we measured the average peak amplitude of the responses to the second to fifth pulses in each train; results were expressed as percent of the control response preceding drug application (see Methods). As noted previously, SR95531 (10 $\mu \mathrm{M})$ was included in the perfusate to block $\mathrm{GABA}_{\mathrm{A}}$ actions of putative non-DAergic mesoaccumbens neurons and antidromic activation of inter-MSN GABAergic connection (Guzman et al., 2003; Taverna et al., 2008).

To discern the intrinsic modulatory effects of DA on the VDNGR, we blocked DA action with the combined application of $\mathrm{SCH} 23390$ (D1 antagonist, $10 \mu \mathrm{M})$ and sulpiride (D2 antagonist, $10 \mu \mathrm{M}$ ). With slower frequency stimulation under current clamp, DA receptor blockade had no effect on EPSP amplitude (Fig. 3A1; $0.2 \mathrm{~Hz}, 93.4 \pm 11.5 \%, n=7$ cells, $P=0.55 ; 1 \mathrm{~Hz}, 95.2 \pm 11.7 \%, n=6$ cells; $10 \mathrm{~Hz}$, $89.6 \pm 8.9 \%, n=7$ cells, $P=0.26$, one-sample $t$-test). Measuring the peak amplitude of the second to fifth EPSPs, there was a suggestion of a weak facilitatory DA effect at 4 $\mathrm{Hz}$ (tonic firing frequency), but this was not significant (110.5 $\pm 7.3 \%, n=8$ cells, $P=0.17$ ). With $20 \mathrm{~Hz}$ (burst firing frequency) stimulation, DA receptor blockade revealed significant inhibition ( $>5 \%$ ) (Fig. $3 A 1,81.6 \pm 1.6 \%, n=11$

values for first pulse and second to fifth pulses for $0.2 \mathrm{~Hz}$ stimulation were the same. The changes after DA receptor blockade (open symbols) or DAT blockade (closed symbols) are expressed as a percent of the preceding control responses. Gray dashed lines indicate no change from control ( $100 \%$ of control). Numbers of recorded cells are in parentheses. Points were connected by polynomial curve fitting; when error bars overlapped, only one side of the bar is shown. DA modulation was only significant ( ${ }^{* *} P<0.01$, one-sample $t$-test) with 20 $\mathrm{Hz}$ stimulation. DA antagonists and DAT blockade had opposite effects. (C) Frequency dependency of the VDNGR depends on DA. Under conditions of full DA receptor blockade (open circles, dashed line), the VDNGR, measured as the average amplitudes of the second to fifth EPSCs, showed no frequency dependence. In contrast, with physiological DA (control condition, gray circles and line) or with enhanced DA effects (DAT blockade, closed circles, black solid line) the frequency dependence became significant (one-way factorial ANOVA). ** indicates $20 \mathrm{~Hz}$ stimulation is significantly different from $0.2,1$ or $4 \mathrm{~Hz}$ stimulation, and * indicates $20 \mathrm{~Hz}$ is significantly different from 0.2 or $4 \mathrm{~Hz}$ stimulation by Scheffe's post-hoc test. 
cells, $P=0.0099$ ); inhibition was evident in nine of the 11 cells. In contrast, the effects of DA receptor blockade on the first EPSP were so variable that there was no significant effect at any stimulus frequency (Fig. 3B, left; $1 \mathrm{~Hz}$, $100.0 \pm 21.1 \%, n=6$ cells, $P=0.99 ; 4 \mathrm{~Hz}, 92.6 \pm 7.5 \%, n=8$ cells, $P=0.33 ; 10 \mathrm{~Hz}, 111.8 \pm 19.3 \%, n=7$ cells, $P=0.53$; $20 \mathrm{~Hz}, 97.8 \pm 12.2 \%, n=11$ cells, $P=0.86)$.

To confirm that the modulation was due to DA release, DA action was selectively enhanced with DAT blocker nomifensine $(10 \mu \mathrm{M})$. This increased the average amplitude of the second to fifth EPSP with $20 \mathrm{~Hz}$ stimulation (Fig. 3A2; $128.0 \pm 6.3 \%, n=19$ cells, $P=0.0002$ ), but had no effect at the slower stimulation frequencies (Fig. 3B, left; $0.2 \mathrm{~Hz}, 98.9 \pm 8.7 \%, n=15$ cells, $P=0.90 ; 1 \mathrm{~Hz}$, $101.1 \pm 11.6 \%, n=7$ cells, $P=0.93 ; 10 \mathrm{~Hz}, 102.2 \pm 3.8 \%$, $n=6$ cells, $P=0.58)$. There was the suggestion of a weak inhibitory effect at $4 \mathrm{~Hz}$, but this was not significant $(91.8 \pm 7.6 \%, n=15$ cells, $P=0.29)$. Similarly, the effects of DAT blockade on the first pulse EPSP, which appeared to have weak facilitatory effects (Fig. $3 \mathrm{~A}$ ), were so varied that no significance was observed at any stimulus frequency (Fig. 3B; $1 \mathrm{~Hz}, 89.4 \pm 10 \%, n=7$ cells, $P=0.35 ; 4 \mathrm{~Hz}$, $107.4 \pm 19.2 \%, n=15$ cells, $P=0.69 ; 10 \mathrm{~Hz}, 97.2 \pm 5.5 \%$, $n=6$ cells, $P=0.63 ; 20 \mathrm{~Hz}, 115.8 \pm 11.0 \%, n=19$ cells, $P=0.14)$. Presumably unreliability of effects on the first EPSP had to do with the variability in concurrent DA release or variability in residual DA remaining from the previous stimulation, so we use only the average amplitude of the second to fifth pulse for testing drug effects in subsequent experiments. In a plot of the average amplitude of the second to fifth EPSPs versus stimulus frequency (Fig. 3B), DA receptor blockade and DAT blockade (DA enhancement) had opposite effects at all stimulus frequencies. The principal effect of co-released DA was facilitation at burst firing frequency $(20 \mathrm{~Hz})$, while there was the suggestion of weak inhibition at lower firing frequencies.

To see whether there was any underlying plasticity in the VDNGR itself, DA effects were blocked with a cocktail of $\mathrm{SCH} 23390$ and sulpiride (Fig. 3C). The absolute amplitude of the average of the 2nd to 5 th pulse EPSPs did not show any dependence on firing frequency $(0.2 \mathrm{~Hz}$, 4.1 $1 \pm 0.7 \mathrm{mV}, n=23$ cells; $1 \mathrm{~Hz}, 2.9 \pm 1.4 \mathrm{mV}, n=6$; $4 \mathrm{~Hz}$, $4.4 \pm 1.1 \mathrm{mV}, n=8 ; 10 \mathrm{~Hz}, 4.9 \pm 1.8 \mathrm{mV}, n=7 ; 20 \mathrm{~Hz}$, $5.6 \pm 1.2 \mathrm{mV}, n=11 ; P=0.64, F=0.64$, one-way factorial ANOVA). In contrast, with physiological DA (the control condition), the VDNGR showed significant frequency dependence $(0.2 \mathrm{~Hz}, 3.6 \pm 1.7 \mathrm{mV}, n=7$ cells; $1 \mathrm{~Hz}, 4.2 \pm 1.1$ $\mathrm{mV}, n=13 ; 4 \mathrm{~Hz}, 4.4 \pm 0.6 \mathrm{mV}, n=24,10 \mathrm{~Hz}, 6.8 \pm 1.3 \mathrm{mV}$, $n=13 ; 20 \mathrm{~Hz}, 7.6 \pm 0.7 \mathrm{mV}, n=31 ; P=0.0014, F=4.77$, one-way factorial ANOVA), and with enhanced DA, the VDNGR showed still greater frequency dependence $(0.2$ $\mathrm{Hz}, 3.9 \pm 0.7 \mathrm{mV}, n=15$ cells; $1 \mathrm{~Hz}, 4.1 \pm 1.0 \mathrm{mV}, n=7 ; 4$ $\mathrm{Hz}, 3.8 \pm 0.6 \mathrm{mV}, n=15 ; 10 \mathrm{~Hz}, 8.6 \pm 1.9 \mathrm{mV}, n=6 ; 20 \mathrm{~Hz}$, $9.0 \pm 1.0 \mathrm{mV}, n=19$ cells; $P<0.0001, F=9.38$, one-way factorial ANOVA). Thus, the frequency dependence of the VDNGR is principally due to DA modulation.

\section{Postsynaptic manipulation eliminated frequency-dependent facilitation}

We used voltage clamp and $\mathrm{Cs}^{+}$-based pipette solutions to block postsynaptic actions selectively. Under voltage clamp, we recorded the VDNGR at the three key stimulus frequencies identified under current clamp, namely $0.2 \mathrm{~Hz}$ (no DA modulation), $4 \mathrm{~Hz}$ (possible DA-mediated inhibition), and $20 \mathrm{~Hz}$ (DA-mediated facilitation). Unless otherwise noted, henceforth drug effects are reported as the percent of the average amplitude of the second to fifth responses. At $0.2 \mathrm{~Hz}$, there was no DA modulation (Fig. 4A1, B; $102.3 \pm 7.6 \%, n=14$ cells, $P=0.76$, one-sample $t$-test) as well as under current clamp, but the inhibition at $4 \mathrm{~Hz}$ became significant $(85.7 \pm 5.3 \%, n=13$ cells, $P=0.016)$. At $20 \mathrm{~Hz}$, the facilitatory effects diminished and were no longer statistically significant $(110.7 \pm 7.3 \%, n=17$ cells, $P=0.15)$. When voltage clamp recordings were done with a $\mathrm{Cs}^{+}$-gluconate intracellular solution, the DA effect at $20 \mathrm{~Hz}$ switched to inhibition (Fig. 4A2, $4 \mathrm{~B} ; 76.4 \pm 3.7 \%$, $n=13$ cells, $P<0.0001$ ), and the inhibition at $4 \mathrm{~Hz}$ remained significant $(82.8 \pm 6.3 \%, n=13$ cells, $P=0.014)$, while no effect was observed at $0.2 \mathrm{~Hz}(95.2 \pm 7.3 \%, n=13$ cells, $P=0.51)$. All cells recorded $(n=13)$ showed significant inhibition with stimulation at $20 \mathrm{~Hz}$. Apparently, postsynaptic depolarization and activation of voltage-gated $\mathrm{K}^{+}$channels were involved in mediating the facilitation. Postsynaptic blockade of facilitation revealed frequencydependent inhibition, which was presumably mediated presynaptically.

The pattern of DA modulation was not changed in adult ( $>6$ week old) animals (Fig. 4C). As in juvenile animals, facilitation was only significant at $20 \mathrm{~Hz}$ stimulation under current clamp recording $(128.3 \pm 11.0 \%, n=7, P=0.032$, one-sample $t$-test), and not significant at $0.2 \mathrm{~Hz}$ (99.0 $\pm 12.2 \%, n=7, P=0.93)$ and $4 \mathrm{~Hz}(97.5 \pm 9.3 \%, n=7$, $P=0.78)$ or under voltage clamp with $\mathrm{K}^{+}$-based pipette solution $(0.2 \mathrm{~Hz}, 98.3 \pm 6.1 \%, n=5, P=0.77 ; 4 \mathrm{~Hz}$, $92.0 \pm 8.7 \%, n=4, P=0.37 ; 20 \mathrm{~Hz}, 115.6 \pm 19.7 \%, n=5$, $P=0.43$ ). Under voltage clamp with a $\mathrm{Cs}^{+}$-based pipette solution, a significant inhibition in the VDNGR was observed only with $20 \mathrm{~Hz}$ stimulation $(83.4 \pm 5.9 \%, n=5$, $P=0.012)$, but not at $0.2 \mathrm{~Hz}(95.1 \pm 9.9 \%, n=5, P=0.61)$ or $4 \mathrm{~Hz}(87.9 \pm 19.8 \%, n=5, P=0.39)$. There was no difference in the modulation between juvenile and adult animals $\left(\mathrm{K}^{+}\right.$-current clamp, $F=0.027, P=0.87 ; \mathrm{K}^{+}$-voltage clamp, $F=0.49, P=0.50 ; \mathrm{Cs}^{+}$-voltage clamp, $F=0.91, P=0.36$, repeated measure ANOVA). These results suggest that DA modulation is nearly mature at 3 weeks of age.

\section{Presynaptic inhibition is D2 mediated}

To show that the DA inhibition of the VDNGR was mediated presynaptically, we blocked postsynaptic DA receptor actions with intracellular G-protein inhibitor GDP $\beta$ S (1-2 $\mathrm{mM}$ ), added to the $\mathrm{K}^{+}$-gluconate pipette solution (Fig. $5 \mathrm{~A}$ ). Under current clamp with $20 \mathrm{~Hz}$ stimulation, DAT blockade was inhibitory $(84.7 \pm 6.0 \%, n=14$ cells, $P=0.023$, onesample $t$-test). This was reversed by the $\mathrm{D} 2$ antagonist sulpiride (10 $\mu \mathrm{M}$; Fig. 5A1, left panel; 115.6 $\pm 9.8 \%, n=6$ 
A1 $\mathrm{K}^{+}$intracellular

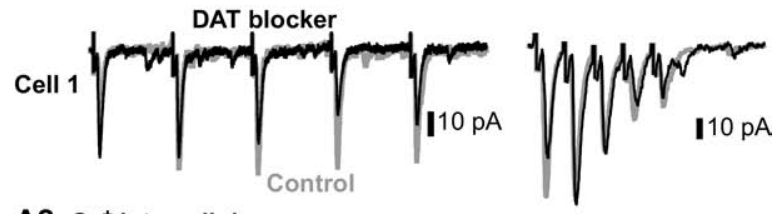

A2 $\mathrm{Cs}^{+}$intracellular
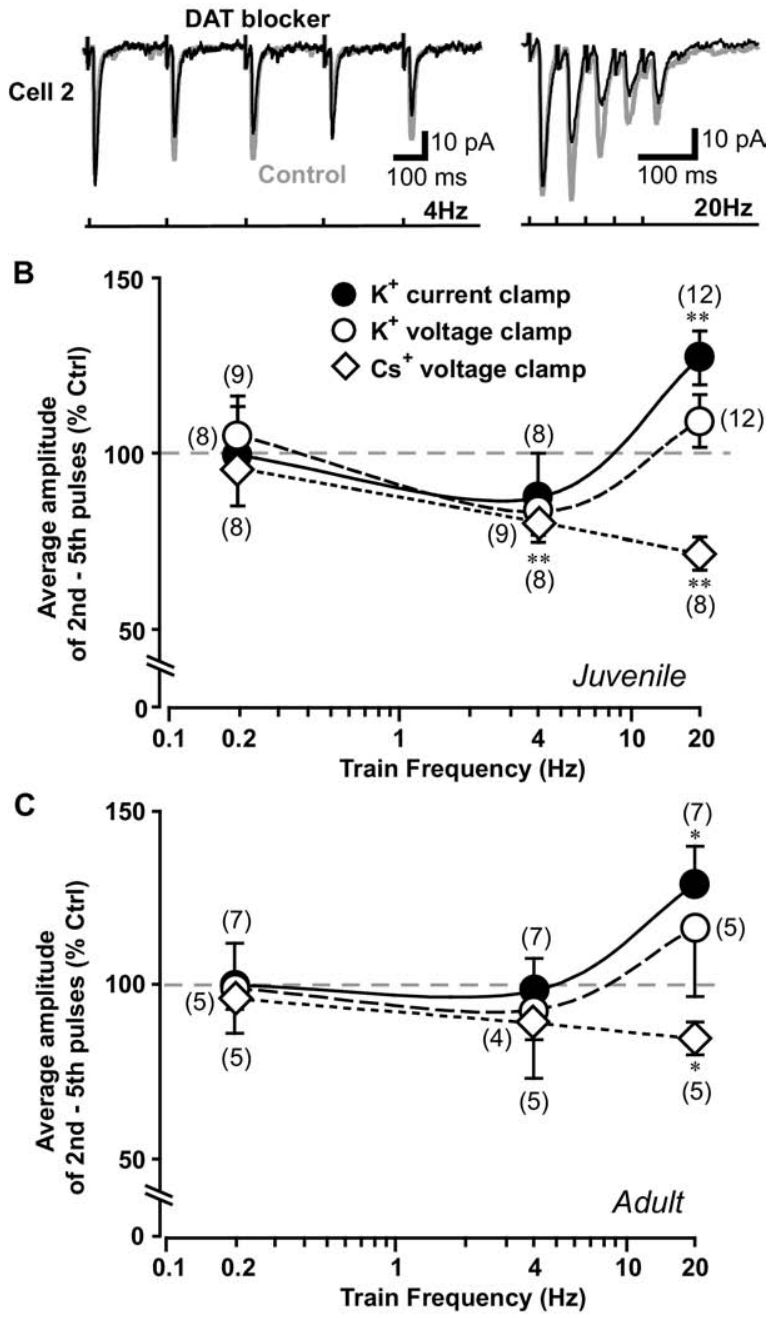

Fig. 4. DA modulation of the VDNGR under voltage clamp. (A) The VDNGR was evoked at $0.2,4$ and $20 \mathrm{~Hz}$, under voltage clamp (holding potential $-85 \mathrm{mV}$ ), with a $\mathrm{K}^{+}$-based (A1) or $\mathrm{Cs}^{+}$-based (A2) intracellular solution. Control traces (gabazine only) are shown in gray and DAT blockade (nomifensine, $10 \mu \mathrm{M}$ ) traces in black. Under voltage clamp, DAT blockade had no effect on the VDNGR. When $\mathrm{K}^{+}$currents were blocked with intracellular $\mathrm{Cs}^{+}$, DAT blockade produced significant inhibition of the VDNGR. (B) Comparison of frequency dependence of DA modulation of the VDNGR in juvenile animals (P20-P34) under current clamp with $\mathrm{K}^{+}$-based intracellular solution $\left(\mathrm{K}^{+}\right.$-current clamp; data shown were re-plotted from previous figure), voltage clamp with $\mathrm{K}^{+}$-based intracellular solution $\left(\mathrm{K}^{+}\right.$-voltage clamp), and voltage clamp with $\mathrm{Cs}^{+}$-based pipette solution $\left(\mathrm{Cs}^{+}\right.$-voltage clamp). Under voltage clamp, with intracellular $\mathrm{Cs}^{+}$, DA action significantly inhibited the VDNGR (** $P<0.01$, one sample $t$-test). (C) Frequency dependency of DA modulation in adult animals (P42-P60). DAT blockade (nomifensine $10 \mu \mathrm{M}$ ) effect on the VTA glutamatergic response was examined at $0.2,4$ and $20 \mathrm{~Hz}$ under current clamp (closed circles), voltage clamp with $\mathrm{K}^{+}$-based pipette solution (open cells, $P=0.025$, unpaired $t$-test between nomifensine only and nomifensine + sulpiride), but not by the D1 antagonist $\mathrm{SCH} 23390(10 \mu \mathrm{M}$; Fig. 5A1, right panel; 89.5 $\pm 10.6 \%$, $n=5$ cells, $P=0.69$, unpaired $t$-test between nomifensine only and nomifensine $+\mathrm{SCH} 23390$ ). These observations suggest that the inhibitory action of DA was mediated presynaptically via D2-like receptors.

To explore this further, we measured the effect of D1 and D2 agonists on the coefficient of variation of EPSC amplitude (Fig. 5B). While this method can distinguish pre-versus postsynaptic modulation, it cannot distinguish between a change in release probability versus a change in the number of release sites (Clements and Silver, 2000). Voltage clamp recordings were done with a $\mathrm{Cs}^{+}$-based pipette solution (to block postsynaptic facilitatory effects), and continuous stimulation at $0.2 \mathrm{~Hz}$. Bath application of the $\mathrm{D} 2$ agonist quinpirole $(5 \mu \mathrm{M})$ reduced average EPSC amplitude (Fig. 5B1, left, 5B2; 73.2 $\pm 7.8 \%, n=6$ cells, $P=0.013$, one-sample $t$-test), while application of the D1agonist SKF81297 (4 $\mu \mathrm{M})$ had no effect (Fig. 5B1, right, $5 \mathrm{~B} 2 ; 107.5 \pm 5.7 \%, n=6$ cells, $P=0.10)$. The coefficient of variation of EPSC amplitude increased after D2 agonist application (Fig. 5B3, left; control 0.43 \pm 0.08 , D2 agonist $0.58 \pm 0.09, n=6$ cells, $P=0.002$, paired $t$-test), while it did not change after D1 agonist application (Fig. 5B3, right; control $0.50 \pm 0.09$, D1 agonist $0.52 \pm 0.08, n=6$ cells, $P=0.37$, paired $t$-test). Thus, synaptically released DA inhibits the VDNGR via presynaptic D2 action. DA neuron terminals bear D2, and not D3 or D4 receptors (Schmitz et al., 2002), so the inhibition was presumably D2 autoreceptor mediated.

\section{Postsynaptic facilitation is D1 mediated}

Since postsynaptic $\mathrm{Cs}^{+}$or GDP $\beta$ S switched the effect of DAT blockade on the VDNGR from facilitation to inhibition, facilitation was presumably mediated postsynaptically. To address this, we bypassed the substrate for presynaptic modulation by injecting a simulated VDNGR current, which was made by averaging EPSCs recorded from three MSNs with $20 \mathrm{~Hz}$ stimulation. Under current clamp, we delivered the simulated VDNGR every $20 \mathrm{~s}$ and examined the effects of bath-applied DA agonists (Fig. 6). We measured the peak amplitude of the five-pulse response (since there was no activity-dependent DA release). DA (10 $\mu \mathrm{M})$ reliably facilitated the simulated mesoventromedial glutamate synaptic current (Fig. 6A, top left, 6B; $111.3 \pm 2.2 \%, n=12$ cells, $P=0.0003$, one sample $t$-test); facilitation was evident in nine of the 12 cells. The D1-agonist SKF81297 (4 $\mu \mathrm{M})$ facilitated the simulated mesoventromedial glutamate current (Fig. 6A, top right, 6B; 113.2 $\pm 4.0 \%, n=11$ cells, $P=0.008)$, while the D2-agonist quinpirole $(5 \mu \mathrm{M})$ had no effect (Fig. 6A, bottom right, 6B; $104.0 \pm 2.5 \%, n=10$ cells, $P=0.35)$. Adding the D2-agonist together with the D1-

circles) and voltage clamp with $\mathrm{Cs}^{+}$-based pipette solution (open diamonds). The control level (i.e. no effect) is indicated by a dashed gray line. Numbers of recorded cells are shown in parentheses. * indicates $P<0.05$, one-sample $t$-test. Both juvenile (B) and adult (C) groups show the same frequency dependence. 
A1

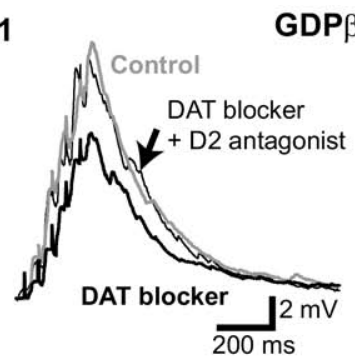

GDP $\beta$ S

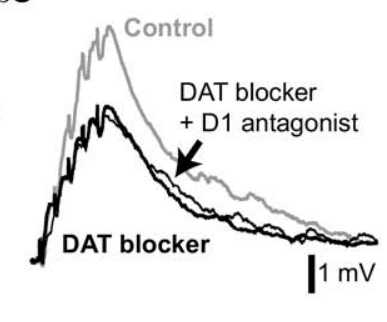

A2

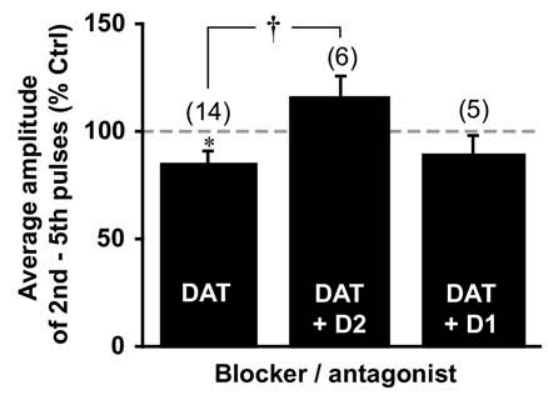

B1
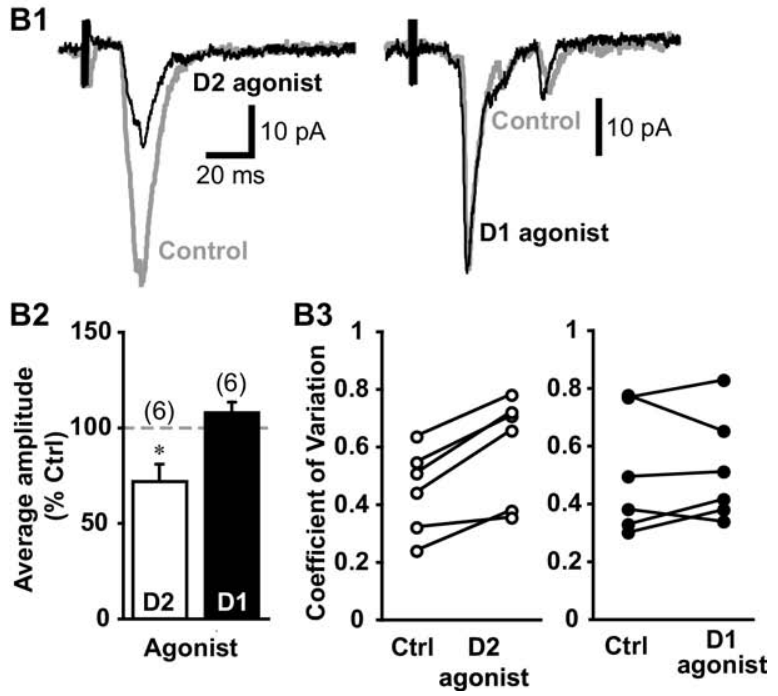

Fig. 5. D2-mediated presynaptic inhibition of the VDNGR. (A) Postsynaptic DA actions were blocked with intracellular GDP $\beta$ S (1-2 $\mathrm{mM}$ ) in order to examine presynaptic DA modulation. Under current clamp (A1), DAT blockade (thick black lines) revealed DA inhibition. This was reversed by application of a D2 antagonist (sulpiride, $10 \mu \mathrm{M}$, left, thin black line), but not a D1 antagonist (SCH23390, $10 \mu \mathrm{M}$, right, thin black line). Control traces are in grey; 10 traces were averaged. Summary data (A2) show DAT blockade (left) produced significant inhibition ( ${ }^{*} P<0.05$, one-sample $t$-test), which was reversed by $\mathrm{D} 2$ (middle), but not D1 antagonist (right) application; ${ }^{\dagger}$ between DAT and DAT + D2 bars indicates $P<0.05$, unpaired-t-test). Data from D1 and D2 antagonists were obtained in separate experiments. (B) Agonist pharmacology under voltage clamp and with intracellular $\mathrm{Cs}^{+}$, to block postsynaptic DA actions completely. The VDNGR was evoked with 0.2 $\mathrm{Hz}$ stimulation, to avoid residual DA effects. (B1) The VDNGR was inhibited by $\mathrm{D} 2$ agonist (quinpirole, $5 \mu \mathrm{M}$, left), but not by D1 agonist (SKF81297, $4 \mu \mathrm{M}$, right panel); 20 traces were averaged. (B2) Summary data show D2 agonist effects were significant (open bar, * $P<0.05$, one-sample $t$-test), while D1 agonist effects were not (closed bar). (B3) A coefficient of variation analysis of the VDNGR with D2 agonist (left, open circles) and D1 agonist (right, closed circles) confirmed that the D2 modulation was presynaptic. Lines connect data points obtained under control and after agonist application for the same cells; the analysis was done on 50 consecutive traces. agonist produced similar facilitation to the D1-agonist alone (Fig. 6A top right, 6B; $119.7 \pm 5.1 \%, n=9$ cells, $P=0.005)$. There was no significant difference between the effects of the D1-agonist alone as compared to the combination ( $n=8$ cells, $P=0.32$, paired $t$-test). Thus, DA facilitates the VDNGR via D1-like receptors. Since there are few D5 receptors (the other member of the D1-like receptor family) in the nAcc (Nicola et al., 2000), the facilitatory effect was likely D1 mediated. The D1 agonist produced facilitation in 8 of the 11 cells, while the cocktail of D1- and D2-agonists produced facilitation in 7 of the 9 cells. While the MSNs that did not respond to DA agonists might have been subject to more extensive washout of intracellular signaling molecules, we found no difference in whole cell and Amphotericin $B$ perforated patch recordings of DA modulation of membrane currents ( $n=6$ cells each, $P=0.78$, unpaired $t$-test). Presumably, the non-responsive cells do not express D1 receptors (see Discussion).
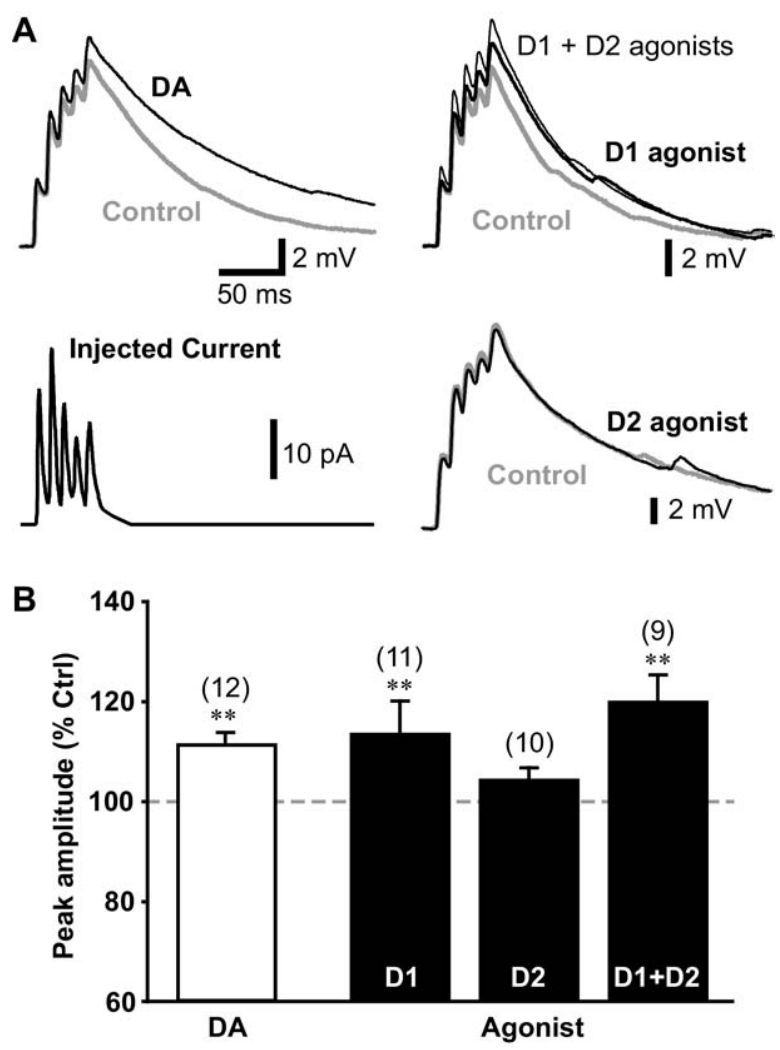

Fig. 6. D1-mediated postsynaptic facilitation of the VDNGR. To isolate postsynaptic DA effects, a current simulating the DA neuron glutamate synaptic current with $20 \mathrm{~Hz}$ stimulation (bottom left, in A) was injected every $20 \mathrm{~s}$ under current clamp. The injected current was obtained by averaging 30 voltage clamp traces from three cells. (A) Traces show that application of DA (10 $\mu \mathrm{M}$, top right) or D1 agonist (SKF81297, $4 \mu \mathrm{M}$, top left, thick black trace) produced facilitation. Addition of D2 agonist (quinpirole, $5 \mu \mathrm{M}$, top left, thin black trace) had no further effect. Similarly, application of D2 agonist alone (bottom right) had no effect. Control traces are in grey; 10 traces were averaged. (B) Summary of DA agonist effects. Numbers of recorded cells are in parentheses; ${ }^{* *} P<0.01$, one-sample $t$-test. 
Postsynaptic facilitation depends on postsynaptic depolarization and involves NMDA receptors

Both our current and voltage clamp recordings showed that postsynaptic depolarization was required for the facilitatory effects of DA on the VDNGR. To examine this further, we evoked EPSCs with $20 \mathrm{~Hz}$ burst stimulation at more depolarized holding potentials and compared the effects of DAT blockade (nomifensine, $10 \mu \mathrm{M}$ ) and DA receptor blockade (SCH23390, $10 \mu \mathrm{M}$, and sulpiride, $10 \mu \mathrm{M})$. DAT blockade (Fig. 7A1, top) had no significant effect at a hyperpolarized membrane potential of $-85 \mathrm{mV}$ (Fig. 7A2; 102.8 $\pm 8.7 \%, n=8$ cells, $P=0.76)$, produced modest facilitation with postsynaptic depolarization to $-75 \mathrm{mV}(111.2 \pm 6.3 \%, n=8$ cells, $P=0.12$ ), and significant facilitation with further depolarization to $-65 \mathrm{mV}(121.3 \pm 6.1 \%, n=7$ cells, $P=0.013)$. With DA receptor blockade (Fig. 7A1, Bottom), there was no significant effect at $-85 \mathrm{mV}$ (Fig. 7A2; 97.3 $26.6 \%, n=6$ cells, $P=0.68)$, modest inhibition at $-75 \mathrm{mV}(85.9 \pm 5.9 \%, n=7$ cells, $P=0.029)$, and significant inhibition at $-65 \mathrm{mV}(78.6 \pm$ $5.4 \%, n=6$ cells, $P=0.0075)$. When plotted versus holding potential, the DAT blockade and DA receptor inhibition effects mirrored each other (Fig. 7A2).

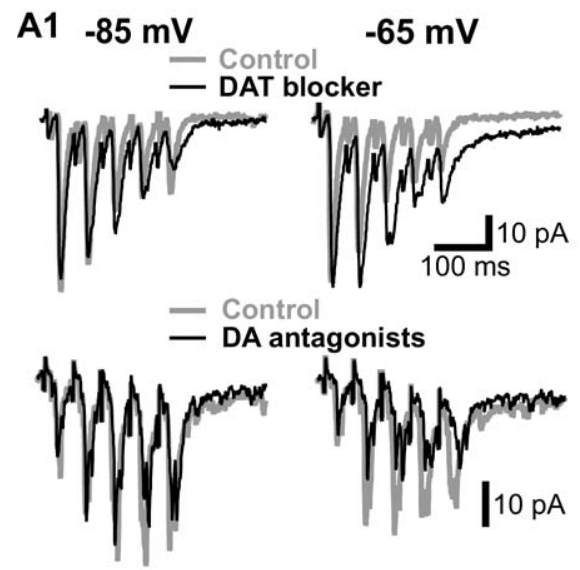

B1

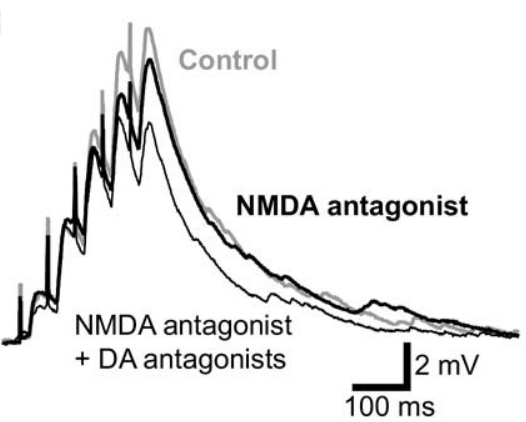

We then asked whether NMDA receptors might be crucial for the postsynaptic facilitation. NMDA receptors also control insertion of D1 receptors at synaptic sites adding further to their potential to facilitate D1 actions (Scott et al., 2006). With DAT blockade under current clamp (maximal DA conditions), the NMDA antagonist APV $(100 \mu \mathrm{M})$ reduced EPSP amplitude significantly (Fig. 7B; 79.1 $\pm 3.2 \%, n=6$ cells, $P=0.021$, one-sample $t$-test). However, blocking DA receptors produced a further reduction (to $71.0 \pm 6.1 \%$ of control, $P=0.0052$, one-sample $t$-test). This further reduction by DA antagonists was significantly different from APV alone ( $P=0.040, n=6$ cells, paired $t$-test). Thus, NMDA receptor activation contributes to the depolarization dependence of the postsynaptic facilitation, but does not account fully for the depolarization dependence.

\section{Voltage gated $\mathrm{K}^{+}$channel closure is critical for postsynaptic facilitation}

We have seen that DA facilitation of the VDNGR was eliminated by postsynaptic $\mathrm{Cs}^{+}$, highlighting the crucial role for voltage-gated $\mathrm{K}^{+}$channels, a subset of which are inhibited by intracellular $\mathrm{Cs}^{+}$(Hille, 2001). We analyzed

A2

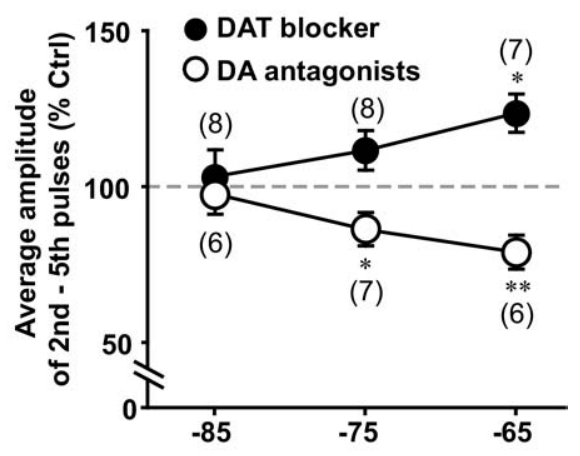

B2

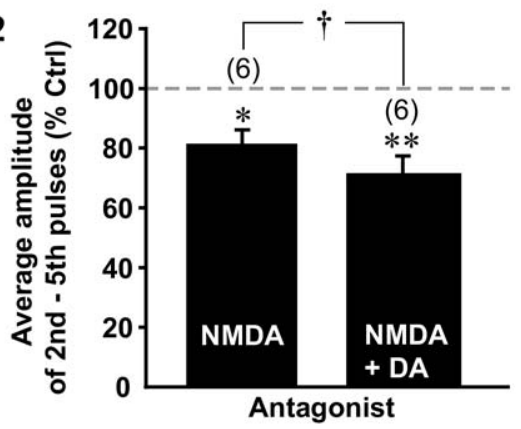

Fig. 7. Postsynaptic facilitation was partly NMDA receptor mediated. (A) Postsynaptic depolarization enhanced DA-mediated facilitation. (A1) Sample traces of DAT blockade (nomifensine, $10 \mu \mathrm{M}$, upper panels) or DA receptor blockade (10 $\mu \mathrm{M} \mathrm{SCH} 23390+10 \mu \mathrm{M}$ sulpiride, lower panels) at a holding potential of $-85 \mathrm{mV}$ (left panels) and $-65 \mathrm{mV}$ (right panels). EPSCs were evoked with $20 \mathrm{~Hz}$ stimulation. Control traces are shown in gray and drug traces in black. Five traces were averaged. (A2) Summary of DAT blockade effect (closed circles) and DA receptor blockade (open circles) at holding potentials of $-85,-75$ and $-65 \mathrm{mV}$. Numbers of recorded cells are in parentheses; ${ }^{*}$ and ${ }^{* *}$ indicate $P<0.05$ and $P<0.01$ respectively (one-sample $t$-test). (B) Postsynaptic facilitation was partly, but not entirely, due to NMDA receptor activation. (B1) Sample traces of NMDA receptor blockade (APV, $100 \mu \mathrm{M}$, black trace) and DA receptor blockade followed by NMDA receptor blockade (100 $\mu \mathrm{M}$ APV $+10 \mu \mathrm{M}$ SCH $23390+10 \mu \mathrm{M}$ sulpiride, thin black trace). All traces were recorded under $10 \mu \mathrm{M}$ nomifensine to enhance DA facilitation; averages of five traces are shown. (B2) Summary of NMDA receptor blockade effects (left) and NMDA and DA receptor blockade (right). Data were obtained from the same sets of cells for both drug applications; ${ }^{*}$ and ${ }^{* *}$ indicate $P<0.05$ and $P<0.01$ respectively (one sample $t$-test); ${ }^{\dagger}$ indicates $P<0.05$ (paired $t$-test). 
the DA modulation further, examining whole cell $\mathrm{K}^{+}$currents, first with a $\mathrm{K}^{+}$-based intracellular solution (Fig. 8A) and then with a $\mathrm{Cs}^{+}$-based intracellular solution (Fig. 8B). With normal intracellular $\mathrm{K}^{+}$, the current-voltage relationship showed both inward and outward rectification (Fig. $8 \mathrm{~A})$. DA $(10 \mu \mathrm{M})$ reduced both inward and outward $\mathrm{K}^{+}$ currents. DA inhibited both inward rectifying currents measured at $-120 \mathrm{mV}$ (Fig. $8 \mathrm{C}$; $56.5 \pm 10.3 \%, n=7$ cells, $P=0.0055)$ and outward currents measured at $+10 \mathrm{mV}$ (70.7 $\pm 7.6 \%, n=7$ cells, $P=0.0087)$. In contrast, whole cell $\mathrm{K}^{+}$currents were mostly blocked with a $\mathrm{Cs}^{+}$-based intracellular solution, and DA had no further effect (Fig. 8B) on either inward (Fig. 8C; $105.7 \pm 12.4 \%, n=7$ cells, $P=0.66$ ) or outward currents $(95.4 \pm 4.0 \%, n=7$ cells, $P=0.29)$. Thus, intracellular $\mathrm{Cs}^{+}$blocked the $\mathrm{K}^{+}$channels mediating the postsynaptic DA facilitation. Taken together with our previous observations, we would conclude that the postsynaptic facilitation was due mainly to $\mathrm{D} 1$-mediated $\mathrm{K}^{+}$channel closure.

\section{DISCUSSION}

We have shown previously that the discrete signal conveyed by medial VTA DA neurons to their targets in the ventromedial nAcc shell consists of a fast excitatory glutamatergic response (Chuhma et al., 2004), the VDNGR. We now show that the majority of DA neurons are immunoreactive for VGLUT2, providing a molecular basis for the cotransmission. Pharmacological isolation of the actions of DA neuron axons in the nAcc reveals no subsecond DA actions, showing that fast transmission in the mesoventromedial projection is solely glutamatergic. The VDNGR shows frequency-dependent facilitation. At tonic firing frequency D2-mediated presynaptic inhibition and D1-mediated postsynaptic facilitation are counterbalanced and so there is no net modulatory effect. At burst-firing frequency, postsynaptic facilitation dominates and coreleased DA augments the VDNGR. The postsynaptic facilitation is both NMDA-receptor dependent and mediated by closure of $\mathrm{K}^{+}$ channels.

\section{Glutamate cotransmission by medial VTA DA neurons}

DA neuron glutamate cotransmission has been controversial. In our initial study of the mesoaccumbens slice preparation, we argued that local perfusion of the VTA with quinpirole, which reduces the excitatory response, was due to D2-mediated inhibition of DA neurons (Chuhma et al., 2004). This was predicated on restricted expression of D2 receptors in DA neurons in the VTA, but more recent studies have identified non-DA VTA neurons expressing D2 receptors (Margolis et al., 2006, 2008). These non-DA neurons, however, do not appear to project to the ventromedial nAcc, as the mesoventromedial projection is almost exclusively DAergic (Ikemoto, 2007).

Glutamatergic neurons are identified by VGLUT expression (Takamori et al., 2000), so the aforementioned studies questioning the significance of VGLUT2 expression in DA neurons argue against cotransmission. Evi-

\section{A $\mathrm{K}^{+}$intracellular}
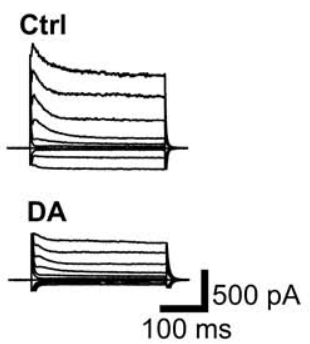

DA
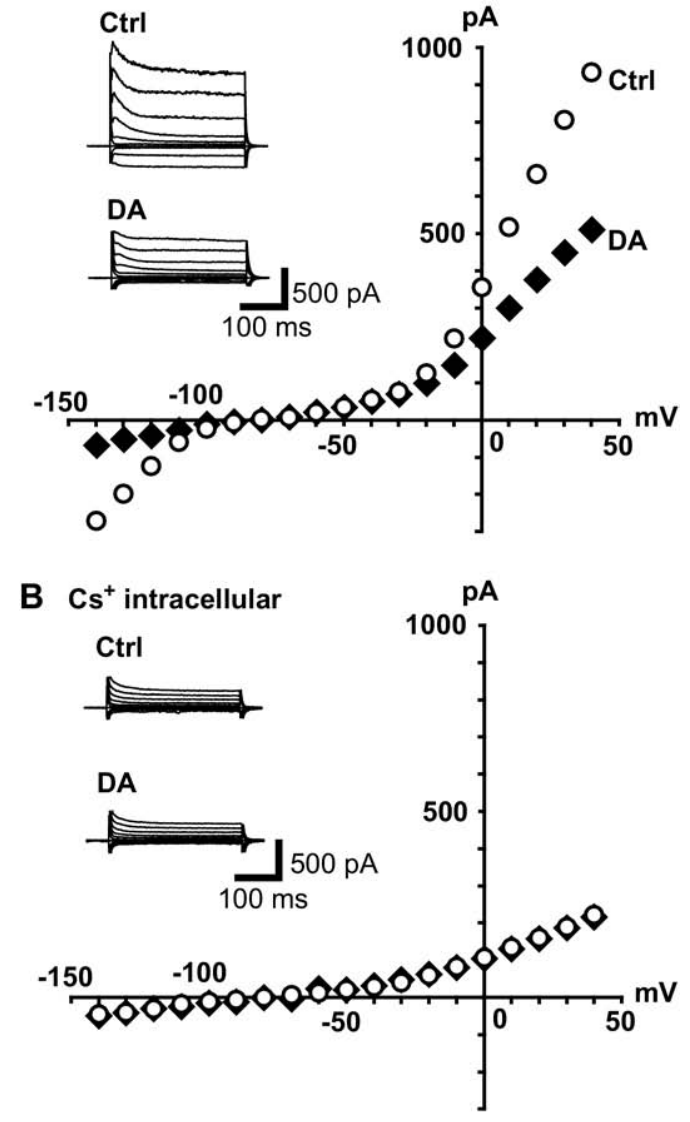

C

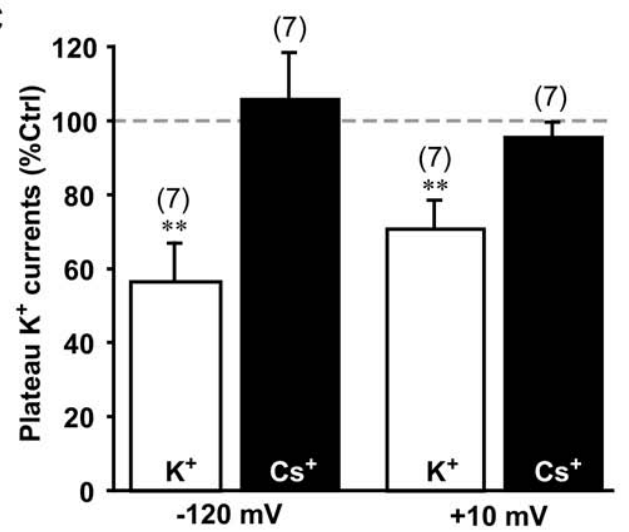

Fig. 8. Postsynaptic DA facilitatory effects were triggered by voltage gated $\mathrm{K}^{+}$channel closure. Whole cell $\mathrm{K}^{+}$currents were recorded under voltage clamp with $\mathrm{K}^{+}$-gluconate $(\mathrm{A})$ or $\mathrm{Cs}^{+}$-gluconate based internal solution (B) at a holding potential of $-80 \mathrm{mV}$, and a series of $10 \mathrm{mV}$ step pulses (300 ms) were delivered. Amplitudes of whole cell $\mathrm{K}^{+}$currents were measured from the average amplitude of the last 20 $\mathrm{ms}$ of the step pulses. Current-voltage relationships of $\mathrm{K}^{+}$currents under control conditions (open circles) and after application of $10 \mu \mathrm{M}$ DA (closed diamonds) are shown. Inset shows sample traces recorded at -140 to $+40 \mathrm{mV}$, with $20 \mathrm{mV}$ steps under control conditions (upper traces) and after DA application (lower traces). (C) DA effects on plateau $\mathrm{K}^{+}$current amplitude with $\mathrm{K}^{+}$-gluconate based pipette solution (open bars) and $\mathrm{Cs}^{+}$-gluconate based pipette solution (closed bars) at $-120 \mathrm{mV}$ (left 2 bars) and $+10 \mathrm{mV}$ (right 2 bars). Numbers of recorded cells are in parentheses; ${ }^{* *}$ indicates $P<0.01$ (one-sample $t$-test). 
dently, discrepancies in the evidence could be due to limits in detecting low-abundance VGLUT2 message, or in difficulties in detecting VGLUT2 protein that is rapidly trafficked away from the cell body to synaptic sites. Immunocytochemical evidence could also be compromised by agonal glutamate release, and the redistribution of VGLUT2-containing vesicles to the plasmalemma, where their fluorescence would be difficult to distinguish from the fluorescence of VGLUT2+ afferent terminals.

To address VGLUT2 expression in DA neurons, we used a perfusion/fixation procedure maintaining continuous glutamate blockade that we have shown previously maintains cellular localization of glutamate immunoreactivity (Sulzer et al., 1998). After validating our immunostaining procedure in its faithful recapitulation of staining in brain regions with more robust VGLUT2 expression, we examined double staining in the VTA and found that in juvenile mice the majority of DA neurons were immunoreactive for VGLUT2, and in adult mice about half of DA neurons were immunoreactive for VGLUT2. This reduction jives with the recognized developmental trajectory in VGLUT2 expression (Mendez et al., 2008). While we did find some glutamatergic (TH-NGLUT2 + ) neurons in both juvenile and adult mice, given the numbers of axons that are severed in the preparation of the mesoaccumbens slice, it seems improbable that this minority of cells could mediate the VDNGR. Moreover, available evidence suggests that these neurons project to cortex, as has been shown by retrograde labeling (Hur and Zaborszky, 2005). Finally, we have found that the VDNGR is nearly eliminated in mice with a DAT-driven conditional knockout of VGLUT2 in DA neurons (Hnasko, unpublished observations). Taken together these observations argue that what we term the VDNGR is indeed due to DA neuron glutamate cotransmission.

\section{Physiological nature of mesoaccumbens cotransmission}

VTA DA neuron stimulation elicited no fast DAergic responses in MSNs. Since DA is widely viewed as a modulatory transmitter, a fast response would not be expected. Nonetheless, focal VTA stimulation elicits a DA mediated subsecond IPSC in DA neurons (Beckstead et al., 2004, 2007), and indeed DA neurons do make inhibitory DAergic connections with other DA neurons (Vandecasteele et al., 2008). However in the nAcc shell, even when we activated DA neuron axons by local stimulation (at the border of the $\mathrm{nAcc}$ ) and enhanced DA action by DAT blockade, subsecond synaptic responses were not seen. Thus, DA neurons appear to have different synaptic actions at their local and projection synapses. Possibly this is due to differential G-protein coupling of D2 receptors in DA neurons versus target neurons (viz. Koyrakh et al., 2005). In target areas, DA appears to act via modulation of other fast transmitters, including glutamate cotransmission in the mesoventromedial DA projection. Consistent with this, ultrastructural observations in the $\mathrm{nAcc}$ indicate that DA neuron varicosities (identified by $\mathrm{TH}$ immunoreactivity) with synaptic specializations are immunoreactive for VGLUT2 suggesting that the bona fide synapses of DA neurons in the nAcc are glutamatergic (Descarries et al., 2008). Taken together with these ultrastructural observations, it seems likely that the frequency dependence of DA modulation of the VDNGR that we have observed involves DA release from multiple varicosities proximate to the subset with glutamatergic actions.

DA had opposing pre- and postsynaptic actions on the VDNGR. Like the cortical afferent input to the nAcc and striatum (Bamford et al., 2004; Brady and O'Donnell, 2004, Goto and Grace, 2005), as well as D2 autoreceptor inhibition of DA release (Benoit-Marand et al., 2001; Phillips et al., 2002; Schmitz et al., 2002), the VDNGR showed D2mediated presynaptic inhibition. Application of DA or DA agonists to nAcc MSNs produces mostly depolarization or facilitatory effects via modulation of voltage-gated $\mathrm{K}^{+}$ channels (Hopf et al., 2003; Perez et al., 2006). While we observed that bath application of DA typically produced a slow depolarization of $\sim 2-3 \mathrm{mV}, \mathrm{CNQX}$ blocked all the synaptic responses evoked by VTA stimulation. Even after DA effects were enhanced by DAT blockade, no direct DA neuron mediated depolarization was evident. This discrepancy probably reflects the difference between bath-applied DA and synaptically released DA. Synaptically released DA is more spatially and temporally restricted (Cragg and Rice, 2004); moreover, we estimate that our focal stimulation of the VTA activates just a few neurons (Chuhma et al., 2004), which would accentuate the difference between bath application and synaptic release. In contrast to DA modulation in the cortex or cortical input to the nAcc (BenoitMarand and O'Donnell, 2008), DA modulation of VTA glutamate transmission was mature at 3 weeks of age, and did not differ significantly between near physiological temperatures and room temperature, at which we conducted most of the experiments.

Facilitation was mediated by postsynaptic D1 receptor activation. However, in about $\sim 15 \%$ of MSNs the VDNGR showed no frequency facilitation. We observed a similar incidence in perforated-patch recordings, arguing against washout effects. More likely, differences in DA receptor expression (Nicola et al., 2000) account for the non-responsive population. In the nAcc shell in adult mice, 47$53 \%$ of MSNs solely express D1 receptors, $36-43 \%$ express solely D2 receptors and $17 \%$ co-express both D1 and D2 receptors, indicating that $64-70 \%$ of MSNs should show D1 responsivity (Bertran-Gonzalez et al., 2008), which is not too different from what we observed. We found that $\sim 25 \%$ of MSNs showed no D1-mediated depolarization with bath application of DA. These MSNs presumably lacked D1 receptors, and thus the substrate for postsynaptic DA facilitation. When a D2 agonist was added to a previously applied D1 agonist, $\sim 50 \%$ of the recorded cells showed further facilitation, presumably due to coactivation of D1 and D2-like receptors, which can synergistically trigger closure of slow A channels (Hopf et al., 2003). Since our sample size was small compared to the anatomical study of Bertran-Gonzalez et al. (2008), some divergence would be expected. In D1 and D2 BAC transgenics it should be noted that not all D1 or D2 expressing neurons 
are fluorescently labeled (Shuen et al., 2008). Thus, the numbers obtained in the anatomical study could be an underestimate. Considering these factors, the proportion of MSNs we observed with D1 actions is consistent with the anatomical data. The variation in postsynaptic DA actions presumably reflects the heterogeneous subpopulations of MSNs expressing D1 and D2 family receptors or both.

DA modulation of the VDNGR was evident only with high-frequency firing. At lower firing frequencies, the D2 presynaptic inhibition and postsynaptic D1 facilitation were counterbalanced and there was no net effect. DA neurons fire spontaneously in the slice, which could contribute to tonic DA effects. However, there was no DA effect with ongoing $0.2 \mathrm{~Hz}$ stimulation, indicating that tonic DA effects were not significant in the mesoaccumbens slice preparation. Therefore, we would argue that the DA effects we observed were due to evoked DA release. When DA neurons fire tonically, the DA concentration in the striatum is uniformly low (Venton et al., 2003), but when DA neurons burst, DA release in target areas reaches much higher concentrations than would be expected from extrapolation based on spike number (Suaud-Chagny et al., 1992). This short-lasting high concentration of DA presumably exceeds autoreceptor-selective DA concentrations and acts postsynaptically to enhance facilitation, overwhelming presynaptic inhibition, resulting in net facilitation.

Contrary to observations in dorsal striatum slices, which lack the in vivo (Venton et al., 2003) frequencydependent build-up of released DA (Cragg and Rice, 2004), nAcc slices show frequency-dependent DA build-up (Zhang and Sulzer, 2004; Zhang et al., 2009a). The same is likely to be the case for measurements in the nAcc in the mesoaccumbens slice. The combination of fast glutamatergic transmission and short lasting DA release with different actions on pre- and postsynaptic sites enables DA neuron bursting to transmit a fast excitatory signal with intrinsic signal enhancement specific to burst firing.

\section{Possible role of the VDNGR}

The VDNGR introduces a fast and coincident excitation to the signaling of DA neurons that encodes temporally precise signals (Chuhma et al., 2004; Lavin et al., 2005; Lapish et al., 2007). The discovery that DA facilitates the VDNGR specifically at burst firing frequencies uncovers a new mechanism through which DA neurons may modulate motivated behavior. Bursts of DA neuron activity in response to a conditioned stimulus (CS) provide incentive salience value to such signals and facilitate the performance of learned behaviors (Berridge, 2007; Zweifel et al., 2008). Indeed, phasic firing of VTA DA neurons seems to be sufficient to induce behavioral conditioning (Tsai et al., 2009). The frequency-dependent DA-mediated enhancement of the VDNGR could specifically attribute motivational value to the CS. Phasic DA, through D1 receptor activation, could potentiate the VDNGR in a subset of nAcc shell neurons facilitating appropriate actions directed towards salient predictive events. The DA-facilitated VDNGR could thus contribute to the generation of "motivational magnets" enhancing the activating properties of the CS (Berridge, 2007), while tonic DA would mediate the effort in reinforcement-seeking behaviors (Salamone et al., 2007). The VDNGR may thus be crucial for the development of the neural representation of the motivational value of the CS.

DA modulation of the VDNGR may be important in psychostimulant addiction. Nomifensine, which like amphetamine and cocaine acts on the DAT, selectively enhanced the VDNGR at burst-firing frequency. Frequencydependent enhancement of the VDNGR could amplify the motivational value of drug-associated cues, and facilitate drug-seeking behaviors. For example, conditioned place preference (CPP) to cocaine was impaired in transgenic mice lacking phasic DA neuron firing (Engblom et al., 2008; Zweifel et al., 2008). DA deficient mice can still show CPP to cocaine (Hnasko et al., 2007) suggesting that the spared DA neuron signal, namely the VDNGR may contribute to CPP to psychostimulants. The VDNGR may thus play a role in attributing incentive salience value to drugassociated cues.

An additional possibility is that VGLUT expression in synaptic vesicles enhances the storage of cotransmitters (Gras et al., 2008); thus, the more extensive expression of VGLUT2 in the ventromedial projection might increase releasable DA stores in mesoventromedial DA neurons. Whether it is directly coincident DA-glutamate release or VGLUT2-enhanced DA storage, the VDNGR or VGLUT2 expression could make the ventromedial DA neurons especially vulnerable to psychostimulant-induced neuroplasticity, and thus be the starting point for the spiral of psychostimulant-induced changes associated with the development of the addicted state (Everitt and Robbins, 2005; Ikemoto, 2007).

Acknowledgments-We are grateful to Dr. Theresa Swayne of the Columbia Optical Microscopy Facility for advice and technical assistance with confocal microscopy, and Emily Rhodes Lowry for initiating the immunocytochemical studies of VGLUT expression in DA neurons. We thank Drs. David Sulzer, Hui Zuang, Daniel Salzman, Inna Gaisler-Salomon, Thomas S. Hnasko and Robert $H$. Edwards for discussion. This work was supported by NIDA grants DA000356 and DA017978 (SR), T32 DA016224 (WC), a NARSAD Young Investigator Award (NC), and the Lieber Center for Schizophrenia Research and Treatment at Columbia University.

\section{REFERENCES}

Bamford NS, Zhang H, Schmitz Y, Wu NP, Cepeda C, Levine MS, Schmauss C, Zakharenko SS, Zablow L, Sulzer D (2004) Heterosynaptic dopamine neurotransmission selects sets of corticostriatal terminals. Neuron 42:653-663.

Beckstead MJ, Ford CP, Phillips PE, Williams JT (2007) Presynaptic regulation of dendrodendritic dopamine transmission. Eur $\mathrm{J}$ Neurosci 26:1479-1488.

Beckstead MJ, Grandy DK, Wickman K, Williams JT (2004) Vesicular dopamine release elicits an inhibitory postsynaptic current in midbrain dopamine neurons. Neuron 42:939-946.

Benoit-Marand M, Borrelli E, Gonon F (2001) Inhibition of dopamine release via presynaptic D2 receptors: time course and functional characteristics in vivo. J Neurosci 21:9134-9141. 
Benoit-Marand M, O'Donnell P (2008) D2 dopamine modulation of corticoaccumbens synaptic responses changes during adolescence. Eur J Neurosci 27:1364-1372.

Berridge KC (2007) The debate over dopamine's role in reward: the case for incentive salience. Psychopharmacology (Berl) 191:391431.

Bertran-Gonzalez J, Bosch C, Maroteaux M, Matamales M, Herve D, Valjent E, Girault JA (2008) Opposing patterns of signaling activation in dopamine D1 and D2 receptor-expressing striatal neurons in response to cocaine and haloperidol. J Neurosci 28:5671-5685.

Brady AM, O'Donnell P (2004) Dopaminergic modulation of prefrontal cortical input to nucleus accumbens neurons in vivo. J Neurosci 24:1040-1049.

Brischoux F, Chakraborty S, Brierley DI, Ungless MA (2009) Phasic excitation of dopamine neurons in ventral VTA by noxious stimuli. Proc Natl Acad Sci U S A 106:4894-4899.

Cameron DL, Wessendorf MW, Williams JT (1997) A subset of ventral tegmental area neurons is inhibited by dopamine, 5-hydroxytryptamine and opioids. Neuroscience 77:155-166.

Chuhma N, Zhang H, Masson J, Zhuang X, Sulzer D, Hen R, Rayport $S$ (2004) Dopamine neurons mediate a fast excitatory signal via their glutamatergic synapses. J Neurosci 24:972-981.

Chung CY, Seo H, Sonntag KC, Brooks A, Lin L, Isacson O (2005) Cell type-specific gene expression of midbrain dopaminergic neurons reveals molecules involved in their vulnerability and protection. Hum Mol Genet 14:1709-1725.

Clements JD, Silver RA (2000) Unveiling synaptic plasticity: a new graphical and analytical approach. Trends Neurosci 23:105-113.

Cragg SJ, Rice ME (2004) DAncing past the DAT at a DA synapse. Trends Neurosci 27:270-277.

Dal Bo G, St-Gelais F, Danik M, Williams S, Cotton M, Trudeau LE (2004) Dopamine neurons in culture express VGLUT2 explaining their capacity to release glutamate at synapses in addition to dopamine. J Neurochem 88:1398-1405.

Descarries L, Bérubé-Carrière N, Riad M, Bo GD, Mendez JA, Trudeau LE (2008) Glutamate in dopamine neurons: synaptic versus diffuse transmission. Brain Res Rev 58:290-302.

Engblom D, Bilbao A, Sanchis-Segura C, Dahan L, Perreau-Lenz S, Balland B, Parkitna JR, Luján R, Halbout B, Mameli M, Parlato R, Sprengel R, Lüscher C, Schütz G, Spanagel R (2008) Glutamate receptors on dopamine neurons control the persistence of cocaine seeking. Neuron 59:497-508.

Everitt BJ, Robbins TW (2005) Neural systems of reinforcement for drug addiction: from actions to habits to compulsion. Nat Neurosci 8:1481-1489.

Gall CM, Hendry SH, Seroogy KB, Jones EG, Haycock JW (1987) Evidence for coexistence of GABA and dopamine in neurons of the rat olfactory bulb. J Comp Neurol 266:307-318.

Geddes JW, Chang NG, Ackley DC, Soultanian NS, McGillis JP, Yokel RA (1999) Postmortem elevation in extracellular glutamate in the rat hippocampus when brain temperature is maintained at physiological levels: implications for the use of human brain autopsy tissues. Brain Res 831:104-112.

Goto Y, Grace AA (2005) Dopaminergic modulation of limbic and cortical drive of nucleus accumbens in goal-directed behavior. Nat Neurosci 8:805-812.

Gras C, Amilhon B, Lepicard EM, Poirel O, Vinatier J, Herbin M, Dumas S, Tzavara ET, Wade MR, Nomikos GG, Hanoun N, Saurini F, Kemel ML, Gasnier B, Giros B, Mestikawy SE (2008) The vesicular glutamate transporter VGLUT3 synergizes striatal acetylcholine tone. Nat Neurosci 11:292-300.

Guzman JN, Hernandez A, Galarraga E, Tapia D, Laville A, Vergara R, Aceves J, Bargas J (2003) Dopaminergic modulation of axon collaterals interconnecting spiny neurons of the rat striatum. J Neurosci 23:8931-8940.

Haber SN, Fudge JL, McFarland NR (2000) Striatonigrostriatal pathways in primates form an ascending spiral from the shell to the dorsolateral striatum. J Neurosci 20:2369-2382.
Hille B (2001) lon channels of excitable membranes. Sunderland, MA: Sinauer.

Hnasko TS, Sotak BN, Palmiter RD (2007) Cocaine-conditioned place preference by dopamine-deficient mice is mediated by serotonin. J Neurosci 27:12484-12488.

Hopf FW, Cascini MG, Gordon AS, Diamond I, Bonci A (2003) Cooperative activation of dopamine D1 and D2 receptors increases spike firing of nucleus accumbens neurons via G-protein betagamma subunits. J Neurosci 23:5079-5087.

Hrabovszky E, Kallo I, Turi GF, May K, Wittmann G, Fekete C, Liposits Z (2006) Expression of vesicular glutamate transporter-2 in gonadotrope and thyrotrope cells of the rat pituitary. Regulation by estrogen and thyroid hormone status. Endocrinology 147:38183825.

Hur EE, Zaborszky L (2005) VGLUT2 afferents to the medial prefrontal and primary somatosensory cortices: a combined retrograde tracing in situ hybridization study. J Comp Neurol 483:351-373.

Ikemoto S (2007) Dopamine reward circuitry: two projection systems from the ventral midbrain to the nucleus accumbens-olfactory tubercle complex. Brain Res Rev 56:27-78.

Jiang Z-G, North RA (1991) Membrane properties and synaptic responses of rat striatal neurones in vitro. J Physiol Lond 443: 533-553.

Joyce MP, Rayport S (2000) Mesoaccumbens dopamine neuron synapses reconstructed in vitro are glutamatergic. Neuroscience 99: 445-456.

Kashani A, Betancur C, Giros B, Hirsch E, El Mestikawy S (2007) Altered expression of vesicular glutamate transporters VGLUT1 and VGLUT2 in Parkinson's disease. Neurobiol Aging 28:568 578.

Kawano M, Kawasaki A, Sakata-Haga H, Fukui Y, Kawano H, Nogami $\mathrm{H}$, Hisano S (2006) Particular subpopulations of midbrain and hypothalamic dopamine neurons express vesicular glutamate transporter 2 in the rat brain. J Comp Neurol 498:581-592.

Korotkova TM, Ponomarenko AA, Brown RE, Haas HL (2004) Functional diversity of ventral midbrain dopamine and GABAergic neurons. Mol Neurobiol 29:243-259.

Koyrakh L, Lujan R, Colon J, Karschin C, Kurachi Y, Karschin A, Wickman K (2005) Molecular and cellular diversity of neuronal G-proteingated potassium channels. J Neurosci 25:11468-11478.

Lammel S, Hetzel A, Häckel O, Jones I, Liss B, Roeper J (2008) Unique properties of mesoprefrontal neurons within a dual mesocorticolimbic dopamine system. Neuron 57:760-773.

Lapish C, Kroener S, Durstewitz D, Lavin A, Seamans J (2007) The ability of the mesocortical dopamine system to operate in distinct temporal modes. Psychopharmacology 191:609-625.

Lavin A, Nogueira L, Lapish CC, Wightman RM, Phillips PEM, Seamans JK (2005) Mesocortical dopamine neurons operate in distinct temporal domains using multimodal signaling. J Neurosci 25: 5013-5023.

Liss B, Roeper J (2007) Individual dopamine midbrain neurons: functional diversity and flexibility in health and disease. Brain Res Rev 50:314-321.

Maher BJ, Westbrook GL (2008) Co-transmission of dopamine and GABA in periglomerular cells. J Neurophysiol 99:1559-1564.

Margolis EB, Mitchell JM, Ishikawa J, Hjelmstad GO, Fields H (2008) Midbrain dopamine neurons: projection target determines action potential duration and dopamine D2 receptor inhibition. J Neurosci 28:8908-8913.

Margolis EB, Lock H, Hjelmstad GO, Fields HL (2006) The ventral tegmental area revisited: is there an electrophysiological marker for dopaminergic neurons? J Physiol 577:907-924.

Matsumoto M, Hikosaka O (2009) Two types of dopamine neuron distinctly convey positive and negative motivational signals. Nature 459:837-841.

Mendez JA, Bourque MJ, Dal Bo G, Bourdeau ML, Danik M, Williams S, Lacaille JC, Trudeau LE (2008) Developmental and target-dependent 
regulation of vesicular glutamate transporter expression by dopamine neurons. J Neurosci 28:6309-6318.

Nicola SM, Surmeier DJ, Malenka RC (2000) Dopaminergic modulation of neuronal excitability in the striatum and nucleus accumbens. Annu Rev Neurosci 23:185-215.

Olson VG, Nestler EJ (2007) Topographical organization of GABAergic neurons within the ventral tegmental area of the rat. Synapse 61 : 87-95.

Perez MF, White FJ, Hu X-T (2006) Dopamine $\mathrm{D}_{2}$ receptor modulation of $\mathrm{K}^{+}$channel activity regulates excitability of nucleus accumbens neurons at different membrane potentials. J Neurophysiol 96: 2217-2228.

Phillips PE, Hancock PJ, Stamford JA (2002) Time window of autoreceptor-mediated inhibition of limbic and striatal dopamine release. Synapse 44:15-22.

Salamone JD, Correa M, Farrar A, Mingote SM (2007) Effort-related functions of nucleus accumbens dopamine and associated forebrain circuits. Psychopharmacology 191:461-482.

Schimchowitsch S, Vuillez P, Tappaz ML, Klein MJ, Stoeckel ME (1991) Systematic presence of GABA-immunoreactivity in the tubero-infundibular and tubero-hypophyseal dopaminergic axonal systems: an ultrastructural immunogold study on several mammals. Exp Brain Res 83:575-586.

Schmitz Y, Benoit-Marand M, Gonon F, Sulzer D (2003) Presynaptic regulation of dopaminergic neurotransmission. J Neurochem 87: 273-289.

Schmitz Y, Schmauss C, Sulzer D (2002) Altered dopamine release and uptake kinetics in mice lacking D2 receptors. J Neurosci 22:8002-8009.

Scott L, Zelenin S, Malmersjö S, Kowalewski J, Markus E, Nairn A, Greengard P, Brismar H, Aperia A (2006) Allosteric changes of the NMDA receptor trap diffusible dopamine 1 receptors in spines. Proc Natl Acad Sci U S A 103:762-767.

Shuen JA, Chen M, Gloss B, Calakos N (2008) Drd1a-tdTomato BAC transgenic mice for simultaneous visualization of medium spiny neurons in the direct and indirect pathways of the basal ganglia. J Neurosci 28:2681-2685.

Spear LP (2000) The adolescent brain and age-related behavioral manifestations. Neurosci Biobehav Rev 24:417-463.

Srinivas S, Watanabe T, Lin CS, William CM, Tanabe Y, Jessell TM, Costantini $F$ (2001) Cre reporter strains produced by targeted insertion of EYFP and ECFP into the ROSA26 locus. BMC Dev Biol 1:4.

Suaud-Chagny MF, Chergui K, Chouvet G, Gonon F (1992) Relationship between dopamine release in the rat nucleus accumbens and the discharge activity of dopaminergic neurons during local in vivo application of amino acids in the ventral tegmental area. Neuroscience 49:63-72.
Sulzer D, Joyce MP, Lin L, Geldwert D, Haber SN, Hattori T, Rayport $S$ (1998) Dopamine neurons make glutamatergic synapses in vitro. J Neurosci 18:4588-4602.

Takamori S, Rhee J, Rosenmund C, Jahn R (2000) Identification of a vesicular glutamate transporter that defines a glutamatergic phenotype in neurons. Nature 407:189-194.

Taverna S, Ilijic E, Surmeier DJ (2008) Recurrent collateral connections of striatal medium spiny neurons are disrupted in models of Parkinson's disease. J Neurosci 28:5504-5512.

Tsai HC, Zhang F, Adamantidis A, Stuber GD, Bonci A, de Lecea L, Deisseroth K (2009) Phasic firing in dopaminergic neurons is sufficient for behavioral conditioning. Science 324:1080-1084.

Vandecasteele M, Glowinski J, Deniau JM, Venance L (2008) Chemical transmission between dopaminergic neuron pairs. Proc Natl Acad Sci U S A 105:4904-4909.

Venton BJ, Zhang H, Garris PA, Phillips PE, Sulzer D, Wightman RM (2003) Real-time decoding of dopamine concentration changes in the caudate-putamen during tonic and phasic firing. J Neurochem 87:1284-1295.

Wassle H, Regus-Leidig H, Haverkamp S (2006) Expression of the vesicular glutamate transporter vGluT2 in a subset of cones of the mouse retina. J Comp Neurol 496:544-555.

Wolfart J, Neuhoff H, Franz O, Roeper J (2001) Differential expression of the small-conductance, calcium-activated potassium channel SK3 is critical for pacemaker control in dopaminergic midbrain neurons. J Neurosci 21:3443-3456.

Yamaguchi T, Sheen W, Morales M (2007) Glutamatergic neurons are present in the rat ventral tegmental area. Eur J Neurosci 25:106118.

Zhang H, Sulzer D (2004) Frequency-dependent modulation of dopamine release by nicotine. Nat Neurosci 7:581-582.

Zhang L, Doyon WM, Clark JJ, Phillips PE, Dani JA (2009a) Controls of tonic and phasic dopamine transmission in the dorsal and ventral striatum. Mol Pharmacol 76:396-404.

Zhang T, Zhang L, Liang Y, Siapas AG, Zhou FM, Dani JA (2009b) Dopamine signaling differences in the nucleus accumbens and dorsal striatum exploited by nicotine. J Neurosci 29:4035-4043.

Zhuang X, Masson J, Gingrich JA, Rayport S, Hen R (2005) Targeted gene expression in dopaminergic and serotonergic neurons of the mouse brain. J Neurosci Methods 143:27-32.

Zweifel LS, Argilli E, Bonci A, Palmiter RD (2008) Role of NMDA receptors in dopamine neurons for plasticity and addictive behaviors. Neuron 59:486-496.

\section{APPENDIX}

\section{Supplementary data}

Supplementary data associated with this article can be found in the online version at: doi:10.1016/j.neuroscience.2009.08.057. 